\title{
Recursos, metodologías y juegos para el desarrollo de la voz infantil en educación primaria
}

\author{
Resources, methodological and games for the development of the \\ child's voice in primary education
}

\section{Jessica Rodríguez Cristino jessicarocri@gmail.com EEPP Sagrada Familia (SAFA) de Linares, España.}

Recibido 01/05/2018

Aceptado 12/06/2019

Revisado 12/06/2019

Publicado 14/06/2019

\section{Resumen}

Este artículo presenta una forma de aprendizaje a través del empleo de una técnica vocal adaptada a las voces infantiles en la etapa de Educación Primaria. El trabajo de la voz en las aulas de educación Primaria aporta muchos beneficios a los discentes, ya que se desarrollan diferentes contenidos que tienen que ver con un buen uso de la voz hablada y cantada, una higiene vocal y corporal, una respiración costodiafragmática, una relajación mental y corporal,

\section{Abstract}

This article presents a form of learning through the use of a vocal technique adapted to children's voices in the stage of Primary Education. The work of the voice in the classrooms of primary education brings many benefits to the students, since different contents are developed that have to do with a good use of the spoken and sung voice, a vocal and corporal hygiene, a cost-diaphragmatic respiration, a mental

Sugerencias para citar este artículo

Rodríguez Cristino , Jessica (2019). Recursos, metodologías y juegos para el desarrollo de la voz infantil en educación primaria. Tercio Creciente, 16, págs. 47-94. https://dx.doi.org/10.17561/rtc.n16.3

RODRÍGUEZ CRISTINO, JESSICA. Recursos, metodologías y juegos para el desarrollo de la voz infantil en educación primaria. Tercio Creciente, julio 2019. $\mathrm{n}^{\circ}$ 16, pp. 47-94. https://dx.doi.org/10.17561/rtc.n16.3 
Recursos, metodologías y juegos para el desarrollo de la voz infantil en educación primaria https://dx.doi.org/10.17561/rtc.n16.3

así como juegos socializadores y de expresión corporal, juegos que les ayudan a descubrir las posibilidades de su cuerpo, un repertorio escolar adecuado para sus posibilidades y a diferentes temáticas. El objetivo fundamental es demostrar que sí se puede aplicar una técnica vocal en niños y que además esto les va a proporcionar muchos beneficios personales, sociales y educativos, puesto que engloba una serie de tareas, juegos y aspectos que repercute de manera favorable en los alumnos y alumnas de Primaria. Una vez expuesta y fundamentada la parte teórica se presentará una investigación a través de las artes llevada a cabo durante varias semanas en un aula de dos líneas del tercer curso de Primaria con un total de 52 alumnos y alumnas en el colegio Sagrada Familia (SAFA) de Linares. Finalmente, para concluir el trabajo se recogen los resultados obtenidos. and corporal relaxation, as well as socializing and body expression games, games that help them discover the possibilities of their body, a school repertoire suitable for their possibilities and different themes. The fundamental objective is to demonstrate that yes you can apply a vocal technique in children and that this will also provide many personal, social and educational benefits, since it encompasses a series of tasks, games and aspects that has a favorable impact on students and students of Primary. Once exposed and substantiated the theoretical part will present a research through the arts carried out for several weeks in a classroom of two lines of the third year of Primary with a total of 52 students in the school Sagrada Familia (SAFA) of Linares. Finally, to conclude the work, the results obtained are collected.

\author{
Palabras clave / Keywords \\ Voz infantil, Técnica vocal en Educación Primaria, Repertorio escolar \\ Childish voice, Vocal Technique Primary Education, School repertoire
}

Sugerencias para citar este artículo

Rodríguez Cristino , Jessica (2019). Recursos, metodologías y juegos para el desarrollo de la voz infantil en educación primaria. Tercio Creciente, 16, págs. 47-94. https://dx.doi.org/10.17561/rtc.n16.3

RODRÍGUEZ CRISTINO, JESSICA. Recursos, metodologías y juegos para el desarrollo de la voz infantil en educación primaria. Tercio Creciente, julio 2019. no 16, pp. 47-94. https://dx.doi.org/10.17561/rtc.n16.3 
Revista de Estudios en Sociedad, Artes y Gestión Cultural

www.terciocreciente.com http://revistaselectronicas.ujaen.es/index.php/RTC
Número 16

Julio 2019

Investigación

DOI: https://dx.doi.org/10.17561/rtc.

https://dx.doi.org/10.17561/rtc.n16.3

\section{Introducción.}

Este artículo parte de una conceptualización del concepto spinoziano del afecto como el trEste artículo da cuenta de una investigación educativa llevada a cabo en el centro "Sagrada Familia” de Linares (Jaén) a partir de la puesta en práctica de una Unidad didáctica destinada al trabajo con las voces infantiles entre otros contenidos relevantes. El desarrollo de las cualidades vocales ha quedado dentro del ámbito educativo un poco olvidado, ya que se le está dando más relevancia a las áreas de contenidos troncales y menos a aquellas que se consideran auxiliares o complementarias.

En cambio, "la voz" es nuestro instrumento de comunicación, de expresión de emociones, para relacionarnos con otros seres humanos, para cantar canciones o recitar poemas y sobre todo, es una parte más de nuestro cuerpo que nos distingue del resto de seres vivos.

Con este trabajo quiero posicionar el empleo de una adecuada técnica vocal en un lugar privilegiado, pues a través de su aplicación en las aulas de Primaria, podemos perfectamente desarrollar contenidos del resto de áreas troncales y complementarias, así como los temas transversales, por ejemplo: la higiene vocal, una adecuada postura corporal, la expresión de emociones y sentimientos a través del canto, etc. También afirmo que el juego, la improvisación, la creatividad, la imaginación, el trabajo cooperativo, las interacciones multidireccionales, el movimiento, la expresión corporal y la experimentación deberán tener un papel crucial en el desarrollo de las clases de música.

Puesto que mi investigación se centra en el empleo de una técnica vocal adecuada con diferentes recursos, metodologías y canciones dentro del aula, voy a comentar brevemente algunos aspectos que son imprescindibles para entender todo lo que seguidamente voy a presentar.

En primer lugar, las voces infantiles poseen unas cualidades específicas que las diferencian de las voces de los adultos. Mi interés en estudiar, ver su desarrollo y aplicar una buena técnica vocal a través del juego y de actividades motivadoras deriva de la importancia que tiene la voz como instrumento y de mi propia experiencia personal.

En relación a las voces infantiles, el tamaño y el desarrollo del órgano de fonación, la extensión y el color de la voz son algunas de las peculiaridades que las diferencian de las de los adultos. Los niños y las niñas no son conscientes del instrumento tan valioso y útil que tienen en su garganta, pues este les permite hablar, comunicarse, expresar sentimientos y emociones y cantar canciones a la vez que se divierten e interactúan. 
Recursos, metodologías y juegos para el desarrollo de la voz infantil en educación primaria https://dx.doi.org/10.17561/rtc.n16.3

En la normativa vigente LOMCE (Ley Orgánica 8/2013, de 9 de diciembre, para la mejora de la calidad educativa), para Primaria y el REAL DECRETO 1630/2006, de 29 de diciembre, por el que se establecen las enseñanzas mínimas del segundo ciclo de Educación Infantil, no se dedica un apartado exclusivo al canto y a la técnica vocal. Sí encontramos en ellos pinceladas de hábitos saludables de higiene, de salud, de la actividad del canto como un recurso lúdico y atractivo para los niños y para las niñas, de habilidades comunicativas y sociales (gracias a la voz como comunicación y expresión de emociones y sentimientos a través de la voz cantada), el trabajo del ritmo, de la entonación y de las cualidades vocales.

Aplicar una la técnica vocal en el aula puede darnos juego a desarrollar muchas habilidades, actitudes y destrezas del alumnado, además de manera interdisciplinar podemos tratar otros temas transversales y relevantes de las diferentes áreas de conocimiento.

El repertorio escolar lo podemos adaptar a las temáticas de nuestras unidades didácticas, a los objetivos de cada una de las sesiones, a los intereses y a las necesidades de nuestro alumnado de Infantil y Primaria. También podemos prevenir problemas vocales como las disfonías y los hábitos posturales incorrectos que afectan a la salud de los más pequeños.

Entre las fuentes bibliográficas que tratan el tema del repertorio escolar destaco Bernal y Calvo (2004, p. 48) que afirman que la canción escolar es "la actividad musical escolar más importante, porque en ella se engloban una serie de aspectos como sensibilidad, afectividad, ritmo y educación tonal. De ahí la importancia de seleccionar un repertorio adecuado”.

Los maestros y las maestras son los encargados de guiar a sus alumnos y a sus alumnas en los procesos de enseñanza y de aprendizaje y además son modelos a seguir por sus discentes. Esto queda justificado por una afirmación que explicita Kaufman (1988, p. 110):

El maestro, al igual que sus alumnos, deberá leer, pensar y cuestionar sus propias ideas, pedir información. Tampoco para él será provechoso un trabajo en solitario. La interacción con otros docentes que comparten su inquietud, que se encuentren en la misma búsqueda, encarando la misma labor, les permitirá enriquecerse profesional y personalmente. Dar y recibir sigue siendo, tanto para los niños como para los adultos, una de las mejores experiencias vitales, esencial para ir construyendo el propio camino que, al decir de Antonio Machado, se hace al andar (Kaufman, 1988, p. 110; citada en Carvajal Pérez y Ramos García, 1999,p. 11).

Es necesario que los niños y las niñas valoren su voz como su instrumento de comunicación oral y musical, pues es "para el niño una forma de expresión emocional” (Echevarría Goñi, 2008, p. 27). Una buena técnica vocal requiere de mucho trabajo por parte del docente y de los discentes, es un esfuerzo compartido, enriquecedor y cooperativo. 
Revista de Estudios en Sociedad, Artes y Gestión Cultural

www.terciocreciente.com http://revistaselectronicas.ujaen.es/index.php/RTC
Número 16

Julio 2019

Investigación

DOI: https://dx.doi.org/10.17561/rtc.

https://dx.doi.org/10.17561/rtc.n16.3

que:

Para ello hay que tener en cuenta muchos aspectos. Tulon I Arfelis (2009, p. 152) afirma

Las sensaciones propioceptivas nos ponen de manifiesto las tensiones musculares a cualquier nivel, el punto de máxima concentración sonora y, en definitiva el mecanismo vocal y la posibilidad de corregir para obtener el resultado esperado, o sea, el control de la voz al que nos conducirá la técnica.

En definitiva, creo conveniente dejar explícita una idea a favor de aplicar una buena técnica vocal de Mansion (1947, p.19) pues nos dice que: "el canto origina una plenitud física y moral que da a la vida todo su valor espiritual”.

He querido una vez fundamentado mi marco teórico verificar que con el empleo de una buena técnica vocal se pueden trabajar muchos contenidos, actitudes, emociones y contenidos musicales que son importantes para el desarrollo físico y psíquico de los niños y además de pueden alcanzar los objetivos propuestos de manera globalizada, cooperativa y divertida.

He llevado a cabo un protocolo de actuación etnográfico educativo basado en las artes, ya que las herramientas que darán la información que se busca es la propia actividad musical que ha sido a su vez el objeto de estudio. Estuve durante un mes y medio analizando las características, posibilidades y limitaciones de mis alumnos y alumnas de Primaria para poder partir de aquello que es relevante e imprescindible para ellos.

Ha sido necesaria la observación directa en todo momento y mi blog de notas para no olvidar detalle del ambiente de la clase y de lo que trabajaban en su aula de música con su tutora, ya que en ese momento yo estaba terminando mis prácticas de grado en Primaria. Esta investigación basada en las artes es de acción y participación, pues yo me he implicado en todo momento en las actividades y juegos llevados a cabo dentro de las clases.

Los instrumentos o las técnicas empleadas en esta investigación son cualitativos, puesto que se valoran los resultados a través de la observación directa en el momento en el que los discentes interactúan, se relacionan, practican, proponen, cambian o no el ritmo de clase, encontramos dificultades que intentamos solucionar entre todos, van descubriendo sus posibilidades, van aprendiendo contenidos, a veces de manera inconsciente, ayudan a sus compañeros, etc. También se tuvieron en cuenta algunos trabajos escritos, las máscaras de diseñaron y por supuesto, la grabación final del resultado.

\section{2.- Objetivos de la investigación basada en las artes}

Esta investigación tiene como objetivo principal poner de manifiesto la relevancia de saber emplear la voz hablada y cantada desde edades tempranas para prevenir y mejorar problemas vocales. 
Recursos, metodologías y juegos para el desarrollo de la voz infantil en educación primaria https://dx.doi.org/10.17561/rtc.n16.3

Lo que se pretende es dejar a un lado los prejuicios que hay sobre el uso de la técnica vocal en los niños y en las niñas y hacer ver los beneficios que esta tiene en su desarrollo corporal, mental y afectivo. Los fines de este trabajo son:

1. Encontrar y verificar una nueva forma de trabajar la técnica vocal mediante el aprendizaje por descubrimiento y significativo en las aulas de Primaria.

2. Dar a conocer los procesos y resultados que se han observado durante y después de la puesta en práctica con las actividades artísticas.

3. Desarrollar y poner en práctica una serie de actividades, juegos y canciones con el fin de conseguir los objetivos didácticos propuestos para esta etapa educativa, en concreto para el desarrollo de las cualidades vocales de los niños.

4. Posicionar el arte como un área crucial, necesaria e interdisciplinar para la Educación Primaria, ya que con el trabajo de un solo contenido estamos trabajando de manera globalizada otros muchos presentes en la Normativa Vigente.

5. Concienciar al profesorado de educación Infantil y Primaria de la relevancia y beneficios de una buena y adaptada educación vocal, postural y de hábitos de higiene.

\section{3.- Marco empírico}

Como ya se ha comentado en la introducción el enfoque metodológico con el que se ha llevado a cabo esta investigación ha sido etnográfico educativo desde una perspectiva basada en las artes al que podríamos llamar "Investigación Educativa Basada en las Artes" (Marín y Roldan: 2014). En este apartado se incluyen los objetivos didácticos y el plan de trabajo junto con las fases desarrolladas a lo largo de este proyecto. 
Recursos, metodologías y juegos para el desarrollo de la voz infantil en educación primaria https://dx.doi.org/10.17561/rtc.n16.3

\section{PLAN DE TRABAJO PARA LA INVESTIGACIÓN}

Mi gran entusiasmo por la música, concretamente por la voz infantil y su presencia en los centros educativos, me ha llevado a realizar una amplia búsqueda en diferentes referencias bibliográficas de grandes profesionales que han escrito acerca sobre las voces infantiles, su desarrollo y su trabajo dentro de las aulas, también he encontrado fuentes relevantes dedicadas a los hábitos vocales, al repertorio escolar y sus tipos y a metodologías educativas para trabajarlo dentro del ámbito educativo. También mi experiencia en diferentes cursos y mi trabajo personal de mi voz me ha dado ideas y herramientas para llevar a cabo este proyecto.

La base de esta investigación está en mi Trabajo Fin De Grado (TFG) y Trabajo Fin De Máster (TFM) realizado durante la carrera y el postgrado que me han dado a conocer y valorar aún más el trabajo de la voz en las aulas, con metodologías activas, cooperativas y lúdicas, apartadas de las tradicionales. Estos trabajos me han aportado un gran marco teórico y muchos conocimientos teóricos y también prácticos.

Lo primero que he hecho es construir mi marco teórico acerca del tema, mi primera fase de investigación ha sido una búsqueda detenida en diferentes fuentes que me han dado conocimientos y herramientas para justificar mi posición sobre cómo se puede aplicar una técnica vocal. Después de estructurar mis fundamentos teóricos he recurrido de nuevo a la Normativa Vigente para ver qué lugar ocupa el trabajo vocal y cómo se propone que se integre en el currículo de Primaria. Atendiendo al Real Decreto 126/2014, de 28 de febrero, por el que se establece el currículo básico de la Educación Primaria

La segunda fase es crucial para esta investigación ha consistido en observar el día a día de unos niños y unas niñas de tercer curso de Educación Primaria junto con su profesora para ver las necesidades e intereses de estos, además he tomado en cuenta el espacio que contamos para la puesta en práctica, así como su mobiliario, sus medidas, la posibilidad que nos ofrece y las limitaciones.

Formé parte del aula en distintas ocasiones durante dos meses mientras iba creando mi marco teórico y construyendo mi unidad didáctica en la cual fundamento y explico lo que quiero trabajar, cómo, por qué, con qué recursos y con qué finalidad. Esta ha ido modificándose según lo observado cada día y lo anotado en el diario de trabajo. La tercera fase ha sido el proceso de preparación de materiales, recursos y la búsqueda de canciones para el desarrollo de las sesiones propuestas.

La cuarta fase ha culminado mi proyecto porque ha sido la puesta en práctica de mi unidad didáctica para verificar si se consiguen los objetivos didácticos que me propuse y si efectivamente es posible aplicar una técnica vocal en los colegios. La observación directa en el aula, la revisión del vídeo grabado durante las sesiones, el trabajo diario, la evolución de los niños y el resultado final de un vídeo serán los instrumentos para evaluar el trabajo realizado. 
Revista de Estudios en Sociedad, Artes y Gestión Cultural

www.terciocreciente.com http://revistaselectronicas.ujaen.es/index.php/RTC
Número 16

Julio 2019

Investigación

DOI: https://dx.doi.org/10.17561/rtc.

https://dx.doi.org/10.17561/rtc.n16.3

\section{FASE 1: FUNDAMENTACIÓN TEÓRICA}

Existen en general pocos estudios sobre la voz infantil y su técnica vocal dentro del ámbito educativo y creo que es un asunto realmente importante, sobre todo para el maestro de música. En cambio, sí hay especialistas en música y medicina que hablan de ello, pero de forma general y no centrándose en la definición de voz infantil ni en su tratamiento desde el descubrimiento, el juego, la improvisación, la expresión corporal y la cooperación dentro de las aulas. Pese a esto, las referencias que he empleado para este trabajo son bastante interesantes, de todas ellas he podido dar forma y enriquecer mi trabajo.

El desarrollo y el estudio de la técnica vocal se han aplicado en general a las voces adultas. Por un lado, esta se aplica con poca frecuencia en las voces infantiles por diversos motivos. Por otro lado, las investigaciones dedicadas al desarrollo y al trabajo de la voz infantil en el ámbito educativo son escasas y tratan fundamentalmente cuestiones relacionadas con la logopedia, pedagogía y los trastornos vocales, es decir, muy pocos son los trabajos destinados firmemente a la técnica de la voz infantil hablada y cantada junto con una serie de juegos que se pueden aplicar en nuestras clases de música.

Se ha justificado la idea de no aplicar una técnica vocal a las voces de los niños y de las niñas con argumentos como: la falta de madurez de la voz infantil para poder soportar trabajos de técnica vocal que requieren bastante constancia y esfuerzo, a los más pequeños no les beneficia una técnica vocal porque esta puede ocasionarles daños en su aparato fonatorio y no es necesario enseñar a cantar a los niños y a las niñas porque ya lo hacen mediante la imitación.

También se dice que ya tendrán tiempo cuando estos sean adultos de adquirir hábitos saludables para cuidar la voz o que existen asuntos más importantes de otras áreas de conocimiento que trabajar la voz en las clases. Se escuchan afirmaciones como que la escuela no es el sitio ideal para trabajar la voz, pues existen los Conservatorios que son los lugares indicados para ello.

Con este trabajo quiero demostrar que es un aspecto crucial para el desarrollo físico y psíquico de los discentes y que es posible adaptar la técnica vocal a la voz hablada y cantada de los más pequeños a través de metodologías activas, lúdicas, cooperativas y significativas para ellos. No podemos olvidar la interiorización de hábitos saludables que deben de desarrollarse desde las edades tempranas.

Entre las referencias bibliográficas acerca de la "voz infantil” señalo algunas de ellas como: Echevarría Goñi (2008, p. 27) que dice que "la voz es para el niño una forma de expresión emocional”. Escudero (1982, p. 9) dice que "la voz es un instrumento musical".

Tulon I Arfelis (2009, p. 13) deja explícito que "la voz es un sonido que, producido por la laringe y amplificado por las estructuras de la resonancia, nos permite la comunicación oral, y alcanza en el canto su máxima expresión y belleza”. Y finalmente, Bustos Sánchez (1995, p. 25) nos muestra una definición completa este concepto y afirma que es: 
Recursos, metodologías y juegos para el desarrollo de la voz infantil en educación primaria https://dx.doi.org/10.17561/rtc.n16.3

Una manifestación expresiva de la persona en su totalidad; a través de ella cada individuo logra expresarse y comunicarse con sus semejantes de una manera singular y única. La voz trasluce la vida psíquica y emocional de quien se expresa, en ella subyace una compleja acción de nervios, huesos, cartílagos y músculos, que implica al cuerpo de manera global. La voz sirve para la emisión de las palabras y estas a su vez lo son para comunicar, intercambiar o compartir nuestras emociones y sentimientos.

En relación a la tesitura infantil y sus características principales es importante recurrir a Diez Martínez (1996, p.53) que nos afirma que:

Si nuestras voces hoy por hoy no alcanzan ciertas tesituras extremas, no debemos empeñarnos en lo inalcanzable sino aprovechar lo que tenemos. Exijamos de nuestro coro infantil lo que sí es capaz de hacer: imprimir a la música que cantan ese vigor rítmico, esa viveza interpretativa, esa alegría meridional que otros no saben lograr.

Este autor realiza un estudio sobre las tesituras infantiles y además nos muestra en sus conclusiones que no solo es importante conocer las posibilidades de la voz sino que también hay que tener en cuenta que el trabajo de la voz debe ser un camino de esfuerzo pero a la vez placentero y en el que cada uno de nosotros desarrollemos nuestros instrumento de manera satisfactoria y sin querer hacer con nuestra voz cosas inalcanzables que pueden destruirla.

Resalto también el estudio sobre la voz infantil y sus cuidados de Molina Hurtado, Fernández González, Vázquez de la Iglesia y Urra Barandiarán (2006) y el artículo de la autora Cañete Pulido (2010) porque en ellos se nos habla de este concepto y sus cualidades principales así como de su cuidado diario.

Lanas (2009) a lo largo de su escrito afirma que las disfonías infantiles se dan frecuentemente en los niños y en las niñas debido al mal uso de la voz y nos dice cómo reconocerlas, cómo prevenirlas y sobre todo cómo mejorarlas. De ahí la necesidad de prevenirlas desde edades tempranas puesto que por desgracia son frecuentes desde edades tempranas.

De Mena González (1994, p. 45) afirma que: "la voz por medio de la palabra es una de los medios esenciales de que dispone el ser humano para expresarse y comunicar los conocimientos, pensamientos, necesidades y sentimientos”. Una voz bien educada nos permitirá comunicarnos más fácilmente y nos dará una mejor presencia en el acto comunicativo. Por este motivo entre otros es conveniente tener en cuenta que no solo un cantante a de cuidar y desarrollar su voz de manera favorable.

La mayoría de las obras comercializadas en la actualidad están destinadas al trabajo de la voz adulta aplicándoles una técnica vocal destinada a ellos. Hay especialistas en campos como la logopedia, la educación, la medicina y la psicología infantil qué si han realizado investigaciones sobre cómo trabajar las voces de los niños mediante el juego y los ejercicios 
Revista de Estudios en Sociedad, Artes y Gestión Cultural

www.terciocreciente.com http://revistaselectronicas.ujaen.es/index.php/RTC
Número 16

Julio 2019

Investigación

DOI: https://dx.doi.org/10.17561/rtc.

https://dx.doi.org/10.17561/rtc.n16.3

prácticos dentro de su especialidad, experiencia y profesionalidad. Pero es necesario reunir todo ello en un proyecto como este para trabajar de lleno las voces infantiles.

Destaco a De Mena González (1994, p. 49) nos aclara que:

La técnica vocal o educación de la voz se caracteriza por la ordenación de una serie de ejercicios conducentes a obtener un mayor rendimiento de las cualidades sonoras de que se dispone, conseguir un mayor dominio en la emisión del sonido y su resonancia y evitar el cansancio físico y la reducción de la potencia de la voz haciéndola obediente a los deseos y dócil a las inflexiones.

Tulon I Arfelis en su libro (2009) propone aclaraciones, ejemplos, así como ejercicios prácticos y consejos que son muy útiles, necesarios e imprescindibles para llevar a cabo una buena técnica vocal en nuestras clases de Infantil y de Primaria. Esta misma autora enseña de forma clara y precisa cómo funcionan cada uno de los órganos fonatorios y otros muchos huesos y músculos para conseguir un trabajo integral de todo nuestro cuerpo y, en definitiva, de nuestra voz.

Heyning (2011, p. 1) dice que cuando los maestros se sienten seguros en lo que respecta al canto sus alumnos y alumnas van a confiar en sus posibilidades y habilidades y las clases van a funcionar de manera efectiva. La confianza y la soltura de los maestros y maestras en el

Cámara Izagirre (2005, p. 106-107) pues afirma que:

El canto es un comportamiento aprendido y el profesorado debe estar preparado para enseñarlo y, a la vez, servir de modelo para el alumnado. El canto puede parecer el aprendizaje de una adquisición tan natural que solamente con la práctica sea suficiente. Sin embargo, una mala orientación vocal puede provocar problemas en la salud de la voz infantil y en el mundo infantil y juvenil estamos asistiendo a un incremento de un mal uso y abusos de la voz.

Otras autoras y autores tratan con detenimiento la técnica vocal pero mediante ejercicios prácticos son Bernal Vázquez y Calvo Niño (2000). Estas presentan una gran variedad de actividades que se pueden aplicar en nuestras aulas. La logopeda Echevarría Goñi (2008) trabaja la voz infantil y sus cuidados mediante actividades y juegos muy recomendados. Dris Ahmed (2010, p. 4) también propone juegos muy útiles para nuestras clases.

Según Cuart (2004, p. 66), la muda de la voz hace que la laringe crezca y que las cuerdas vocales aumenten de tamaño. Las voces de las niñas van consiguiendo más plenitud y la de los niños se encuentran en una octava más baja, de manera que se van acercando a su tesitura natural de voz masculina. En este periodo hay que tener un especial cuidado con la voz por eso como dice esta autora (2004, p. 66): "no conviene forzarla para cantar, procurando también no gritar, pues un esfuerzo inadecuado puede producir nódulos vocales”. 
Recursos, metodologías y juegos para el desarrollo de la voz infantil en educación primaria https://dx.doi.org/10.17561/rtc.n16.3

Esto y otros cambios corporales hacen que la voz del niño adolescente se haga más grave y se diferencie de la voz femenina. Cuanto más largo sea ese período de "muda", es decir, de fabricación de hormonas masculinas, más oscura y por lo tanto más grave será su voz.

El aparato vocal es un sistema complejo, pues como dice Mansion (1947, 27): "En él están comprendidos un número incalculable de nervios, vasos sanguíneos, cartílagos, etc.” Como apunta Mansion (1947, p. 27): "Es indispensable para un cantante conocer bien su instrumento de trabajo".

Según De Mena González (1996, p. 25) diferenciamos: el "activador” (aparato respiratorio), el "vibrador" (aparato laríngeo) y el "resonador" (aparato fonador), aunque en su función sean inseparables. Estos aparatos con la ayuda de ciertos músculos y huesos así como el cerebro van a permitir mediante un trabajo correcto y coordinado que se produzca la emisión de la voz.

La voz es importante para el acto del habla porque sin ella no se produciría y habría que buscar otros sistemas de comunicación a través de los cuales no haya que emplear el lenguaje oral. Una voz bien educada nos permitirá comunicarnos más fácilmente y nos dará una mejor presencia en el acto comunicativo. La educación de la voz debe ser uno de los aspectos básicos y relevantes que se deben trabajar desde la escuela. Los niños y las niñas tienen que saber cómo funciona su instrumento y cómo deben de utilizarlo en cada acto de comunicación.

El uso de la voz habla es muy habitual desde que los niños y las niñas comienzan a pronunciar sus primeros sonidos con la intención de llamar la atención o de comunicar algo. Escudero (1987, p. 33) nos dice que es importante desarrollar una buena articulación de las palabras, la correcta posición corporal, la agilidad de las lengua y de los labios y los ejercicios de extensión tonal para el desarrollo de la voz.

La autora De Mena González (1996, p. 75) afirma que:

Para la educación hablada es necesario tiempo y paciencia tanto por parte del profesor de ortofonía, (persona que se encarga de educar y reeducar la voz hablada mediante una serie de procedimientos y técnicas apropiados a cada caso), como por parte de la persona interesada en reeducarse la voz.

Esta misma autora señala las técnicas de tratamiento a seguir para educar o reeducar la voz hablada pero que en mi opinión también son aptos para la voz cantada:

- Técnica de respiración

- Técnica vocal 
Revista de Estudios en Sociedad, Artes y Gestión Cultural

www.terciocreciente.com http://revistaselectronicas.ujaen.es/index.php/RTC
Número 16

Julio 2019

Investigación
ISSN: 2340-9096

DOI: https://dx.doi.org/10.17561/rtc.

https://dx.doi.org/10.17561/rtc.n16.3

- Técnica de articulación

- Colocación de la lengua y labios para la emisión de los fonemas.

- Articulación de las sílabas y las palabras.

- Entonación de los fonemas, palabras y frases.

- Diferentes inflexiones de la voz.

Es evidente que para hablar bien se necesita una buena técnica vocal que encamine el instrumento por el buen camino para evitar problemas vocales en el futuro, desde la escuela podemos prevenirlos a través del juego y las canciones infantiles.

La técnica vocal se puede definir como un trabajo global con nuestro cuerpo y en especial con el aparato fonador adecuado y adaptado a todas nuestras posibilidades y cualidades vocales. Se emplean metodologías apropiadas para desarrollar, adquirir y mejorar la concentración, la escucha activa, la respiración costodiafragmática, los estiramientos, la vocalización y la relajación corporal y mental.

De Mena González (1994, p. 49) nos dice una afirmación importante acerca de la educación de las voces infantiles que se debe considerar en este trabajo: "la voz puede y debe controlarse desde niño cuidando aprender a respirar, a pronunciar con exactitud las vocales y consonantes, a modular y a matizar y a no dejar caer las sílabas finales”.

Según Montserrat Sanuy (1996), para trabajar "la voz" de los niños y de las niñas es necesario seguir ocho pasos que creo convenientes tenerlos en cuenta en este trabajo:

1. Coordinación-disociación de movimientos: Practicamos ejercicios para tomar conciencia de la independencia funcional entre los distintos miembros del cuerpo. Trabajamos cada miembro del cuerpo tensando y relajando cada uno de ellos.

2. Tono muscular: Trabajamos con la musculatura de nuestro cuerpo. Para ello realizamos ejercicios con las piernas, hacemos movimientos circulares de tobillos, trabajamos con el tronco, con brazos, con las muñecas y el cuello.

3. Postura corporal: Trabajamos una correcta posición para cantar correctamente. Se trata de encontrar el equilibrio sobre el eje corporal, mediante una posición adecuada sin agarrotar ninguna parte del cuerpo y mantenerlo relajado. 
Recursos, metodologías y juegos para el desarrollo de la voz infantil en educación primaria https://dx.doi.org/10.17561/rtc.n16.3

4. Respiración: A través de juegos, los discentes deben de conseguir una respiración costodiafragmática (descenso del diafragma, llenando la zona costolateral y extender los pulmones).

5. Emisión y articulación: Trabajar la musculatura facial, colocar la boca en su posición correcta.

6. Resonancia: Los niños y las niñas deben ser conscientes de la vibración del sonido que se da en su cabeza cuando cantan correctamente.

7. Justeza rítmica y entonación: Este aspecto se consigue con el trabajo diario de una buena técnica vocal y un autocontrol auditivo.

8. Expresión: canción indicada. dice que:

Hay que tener en cuenta unas palabras de Cámara Izagirre (2005, p. 106-107) pues

El canto es un comportamiento aprendido y el profesorado debe estar preparado para enseñarlo y, a la vez, servir de modelo para el alumnado. El canto puede parecer el aprendizaje de una adquisición tan natural que solamente con la práctica sea suficiente. Sin embargo, una mala orientación vocal puede provocar problemas en la salud de la voz infantil y en el mundo infantil y juvenil estamos asistiendo a un incremento de un mal uso y abusos de la voz.

Los maestros de música tenemos que estudiar nuestra voz y la nuestros alumnos y alumnas y por supuesto debemos de conocer cómo aplicar una buena técnica vocal a sus voces para educarlas.

Finalmente, he de decir que es importante el rol del profesor como ayudante, animador y guía de sus alumnos y de sus alumnas a lo largo de sus procesos de enseñanza y de aprendizaje, ya que las expectativas del docente van a influir de forma negativa o positiva en el desarrollo vocal y expresivo de sus alumnos y de sus alumnas.

Existen una serie de juegos válidos para desarrollar una buena técnica vocal en Educación Infantil y en Primaria, incluidos en otros trabajos que he realizado anteriormente como son mi TFG y TFM en la Universidad de Jaén. He recogido algunos de ellos: 
https://dx.doi.org/10.17561/rtc.n16.3

Cuadro 1. Actividades para la flexibilidad y tesitura vocal

\section{Actividades para la flexibilidad y tesitura de la voz. (Bernal Vázquez y Calvo Niño, 2000ª ${ }^{\mathrm{a}}$ )}

En círculo se lanzan una pelota de ping - pong y emiten un sonido cada vez que rebota

Colocar la mano sobre la garganta, sentir las vibraciones de las cuerdas vocales mientras emiten un sonido

Escoger cada uno una palabra y cantarla de manera personal

Inspirar, producir un sonido continuado y andar; pararse cuando deba, respirar de nuevo

Cantar sonidos: largos, cortos, fuertes, pianos, rápidos, lentos etc. Y buscarlos con boca cerrada

Los niños en círculo. El maestro le da un objeto a uno de ellos, que cantará un sonido; este lo pasa a otro compañero y deberá cantar el mismo sonido, así sucesivamente 
Recursos, metodologías y juegos para el desarrollo de la voz infantil en educación primaria https://dx.doi.org/10.17561/rtc.n16.3

Tabla 2. Ejercicios de calentamiento (Propuesta personal)

\begin{tabular}{|c|c|}
\hline Actividades de calentamiento & Descripción \\
\hline El pase de pelotas & $\begin{array}{l}\text { Todos se colocan en círculo. El docente da una pelota al alumnado } \\
\text { para que se la pasen los unos a los otros diciendo el nombre del } \\
\text { compañero al que le dan la pelota. Vamos variando la voz en altura, } \\
\text { intensidad, duración etc. }\end{array}$ \\
\hline ¿Qué canto? & $\begin{array}{l}\text { Cada niño tararea una canción y el resto debe adivinar el título de } \\
\text { esta }\end{array}$ \\
\hline ¡Es mi cerebro! & $\begin{array}{l}\text { En parejas, un compañero da órdenes al otro que debe hacer lo que } \\
\text { este que es su “cerebro” le indica. Ejemplo: ¡Levanta los brazos } \\
\text { mientras das un grito! }\end{array}$ \\
\hline Bola de fuego & $\begin{array}{l}\text { Imaginamos que una bola de fuego va pasando por las distintas } \\
\text { partes de nuestro cuerpo y la controlamos. }\end{array}$ \\
\hline Escondite inglés & $\begin{array}{l}\text { Jugamos al pollito inglés tradicional con una variante. "El que } \\
\text { contaba, ahora dice una emoción, por ejemplo alegría" y los que } \\
\text { quieren llegar al final deben de expresar de manera clara y grande } \\
\text { esta emoción y aguantar hasta el que estaba de espaldas quiera. Si no } \\
\text { aguanta vuelve a empezar. }\end{array}$ \\
\hline ¡Viva la pasarela! & $\begin{array}{l}\text { Nos colocamos por parejas. A continuación cogemos de una caja los } \\
\text { disfraces o complementos necesarios para desfílar cómo modelos } \\
\text { mientras juntos entonamos una canción }\end{array}$ \\
\hline 4 Sillas para 4 personas & $\begin{array}{l}\text { Debemos de ocupar una de las sillas sin coincidir con los demás. } \\
\text { Hay que estar atento a las intenciones de los otros y a las propias. }\end{array}$ \\
\hline Carrera despacio-despacio & $\begin{array}{l}\text { Debemos de llegar a la meta lo más tarde posible. Los primeros en } \\
\text { llegar son eliminados, el último que quede gana la carrera. } \\
\text { OBJETIVO: NO LLEGAR A LA META ANTES QUE LOS } \\
\text { DEMÁS. }\end{array}$ \\
\hline Fotos para crear personaje & $\begin{array}{l}\text { Elegimos una foto, pensamos en el personaje y lo representamos con } \\
\text { los elementos, centros y características que imaginamos acorde a la } \\
\text { fotografía. Nos hacen tres o cuatro preguntas para responder según el } \\
\text { personaje al que estamos imitando. }\end{array}$ \\
\hline $\begin{array}{l}\text { Adoptamos letras de poesías o } \\
\text { canciones a un personaje }\end{array}$ & $\begin{array}{l}\text { Elegimos una foto y un poema o una canción. Hacemos la imitación } \\
\text { del personaje mientras recitamos la letra. Luego se hizo cantando (la } \\
\text { canción). }\end{array}$ \\
\hline Juego del pañuelo & $\begin{array}{l}\text { Jugamos al juego tradicional del pañuelo. Hacemos dos equipos. Un } \\
\text { alumno/a agarra el pañuelo. Se dice un número y salen uno de cada } \\
\text { equipo al llegar al pañuelo comienzan a interaccionar. Cuando el que } \\
\text { tiene el pañuelo dice "ya" el primero que lo coja se lo lleva teniendo } \\
\text { cuidado de que el otro no lo toque porque si no pierde. }\end{array}$ \\
\hline Música a favor o en contra & $\begin{array}{l}\text { Se pusieron dos músicas, se hicieron dos equipos, un equipo debe } \\
\text { hacer escena y movimiento a favor de la música y el otro en contra. }\end{array}$ \\
\hline
\end{tabular}


ISSN: 2340-9096

DOI: https://dx.doi.org/10.17561/rtc.

https://dx.doi.org/10.17561/rtc.n16.3
Investigación

Tabla 3. Ejercicios de calentamiento (Propuesta personal)

\begin{tabular}{|l|l|}
\hline \multicolumn{1}{|c|}{$\begin{array}{c}\text { Actividades de calentamiento } \\
\text { (Cara y cuello) }\end{array}$} & \multicolumn{1}{c|}{ Descripción } \\
\hline $\begin{array}{l}\text { Movimientos de cuello al modo de los } \\
\text { autómatas. }\end{array}$ & $\begin{array}{l}\text { Le damos órdenes cómo: } \\
\text { El robot dice "si" con la cabeza (lentamente) } \\
\text { El robot dice "no" } \\
\text { El robot dice "a veces" etc. }\end{array}$ \\
\hline Sonrisas de oreja a oreja & $\begin{array}{l}\text { Los niños intentan conseguir la más amplia de } \\
\text { las sonrisas. Vuelven con suavidad a su } \\
\text { posición inicial }\end{array}$ \\
\hline Una hormiga pasea por mi cara & $\begin{array}{l}\text { Un montón de hormigas pasan por su cara, } \\
\text { para ello realizarán suaves masajes con las } \\
\text { yemas de los dedos }\end{array}$ \\
\hline Muecas & \begin{tabular}{l} 
Los niños recrean todo tipo de personajes \\
\hline La serpiente
\end{tabular} \\
& $\begin{array}{l}\text { Los niños tienen que sacar la lengua y moverla } \\
\text { a un lado y a otro, con movimientos rápidos }\end{array}$ \\
\hline
\end{tabular}

Tabla 4. Actividades para relajación corporal y mental. Echevarría Goñi (2008: 56-63)

\begin{tabular}{|l|l|}
\hline \multicolumn{1}{|c|}{ Actividades relajación } & \multicolumn{1}{c|}{ Descripción } \\
\hline Oso dormilón & $\begin{array}{l}\text { Los niños son osos que están tumbados en el suelo y } \\
\text { empiezan a mover lentamente las partes de su cuerpo de } \\
\text { izquierda a derecha y de arriba hacia abajo dejándolas sin } \\
\text { tensión. }\end{array}$ \\
\hline Vals de las mariposas & $\begin{array}{l}\text { Al son de la música, las mariposas bailan con sus alas, } \\
\text { muy lentamente. Los niños mueven sus brazos con } \\
\text { suavidad y con las articulaciones relajadas. }\end{array}$ \\
\hline El juego de las marionetas & $\begin{array}{l}\text { Se convierten en marionetas (cuerpo con cierta rigidez } \\
\text { muscular), "ahora que las marionetas tienen los hilos muy } \\
\text { tensos, deben caminar con la punta de los pies, con los } \\
\text { brazos tiesos a lo largo del cuerpo". A la señal: se sueltan } \\
\text { los hilos, los niños tienen que doblar el cuerpo; la cabeza } \\
\text { y los brazos adquieren un movimiento pendular. }\end{array}$ \\
\hline
\end{tabular}


Recursos, metodologías y juegos para el desarrollo de la voz infantil en educación primaria https://dx.doi.org/10.17561/rtc.n16.3

Tabla 5. Actividades para relajación corporal (Propuesta personal)

\begin{tabular}{|l|l|}
\hline \multicolumn{1}{|c|}{$\begin{array}{c}\text { Actividades para relajación } \\
\text { corporal }\end{array}$} & \multicolumn{1}{c|}{ Descripción } \\
\hline Monstruo & $\begin{array}{l}\text { Relajación del cuerpo (empezamos por los tobillos } \\
\text { haciendo círculos, incorporamos las rodillas, la cadera, } \\
\text { los hombros, los brazos, las manos, el cuello, la } \\
\text { cabeza...) }\end{array}$ \\
\hline Caminamos & $\begin{array}{l}\text { Todos caminan, al sonido de una palmada cambia de } \\
\text { dirección, al de dos palmadas siguen caminando } \\
\text { agachados, a las tres palmadas van muy agachados. Con } \\
\text { esto trabajamos la atención y los niños se evaden de la } \\
\text { realidad y se relajan }\end{array}$ \\
\hline Actividad: & $\begin{array}{l}\text { Todos empiezan a caminar, cuando el docente dice } \\
\text { iSTOP! Se paran y ponen en tensión las distintas partes } \\
\text { Tel cuerpo, al decir ¡YA! Deben quitar la tensión (gran } \\
\text { suspiro) y seguir caminando }\end{array}$ \\
\hline
\end{tabular}

Tabla 6. Actividades para una buena respiración costo-diafragmática. De la autora Sagrario Echevarría Goñi (2008:79-80)

\section{Pautas para conseguir una correcta posición corporal.}

(Tulon Arfelis, 2009: 76-78)

No rigidez ni tensión corporal

Sí debe hacer distensión, flexibilidad, relajación y equilibrio. (El peso cae sobre las piernas y los pies no se despegan del suelo)

Cuerpo atraído hacia abajo por la gravedad de la Tierra, es decir, hay que alinear el cuerpo y mantenerlo vertical y recto 
ISSN: 2340-9096

DOI: https://dx.doi.org/10.17561/rtc.

https://dx.doi.org/10.17561/rtc.n16.3
Investigación

Cuadro 2. Pautas y pasos para conseguir una correcta posición corporal

\begin{tabular}{|c|c|c|}
\hline $\begin{array}{c}\text { Respiración } \\
\text { costo-diafragmática }\end{array}$ & Descripción & Otros ejercicios \\
\hline El túnel & $\begin{array}{l}\text { Los discentes ponen los brazos } \\
\text { cruzados o extendidos a lo largo de } \\
\text { una mesa y a la altura de su } \\
\text { estómago. A la vez que deshinchan } \\
\text { el vientre tienen que silbar y después } \\
\text { hinchan el estómago mientras } \\
\text { inspiran por la nariz }\end{array}$ & $\begin{array}{l}\text {-Soplar en un globo } \\
\text {-Imaginar que olemos una } \\
\text { flor y nos encanta su perfume } \\
\text {-Practicar el jadeo de un perro } \\
\text { - Imaginamos inflar la rueda } \\
\text { de una bicicleta }\end{array}$ \\
\hline La gallinita ciega & $\begin{array}{l}\text { Los niños se colocan por parejas. } \\
\text { Uno de ellos con los ojos cerrados se } \\
\text { coloca tras uno de sus compañeros. } \\
\text { El niño coloca sus manos sobre el } \\
\text { vientre del compañero para percibir } \\
\text { su respiración mientras tiene sus ojos } \\
\text { cerrados; después coloca sus manos } \\
\text { sobre su vientre para comparar }\end{array}$ & $\begin{array}{l}\text {-Imaginamos que somos el } \\
\text { lobo malvado de los tres } \\
\text { cerditos y que queremos } \\
\text { derribar la casa de estos } \\
\text {-Imaginar que estamos } \\
\text { comiendo sopa y soplamos a } \\
\text { la cuchara para que no } \\
\text { queme. Después nos } \\
\text { tomamos la cucharada }\end{array}$ \\
\hline La rana tranquila & $\begin{array}{l}\text { Los niños y las niñas se colocan de } \\
\text { cuclillas, con las manos en sus } \\
\text { rodillas. En esta posición los } \\
\text { discentes inspiran y espiran tal y } \\
\text { cómo se les ha enseñado }\end{array}$ & $\begin{array}{l}\text {-Es nuestro cumple y } \\
\text { apagamos las velas de nuestra } \\
\text { tarta de cumpleaños } \\
\text {-Somos un ventilador y } \\
\text { soplamos para hacer aire }\end{array}$ \\
\hline
\end{tabular}


Recursos, metodologías y juegos para el desarrollo de la voz infantil en educación primaria https://dx.doi.org/10.17561/rtc.n16.3

Tabla 7. Actividades para las cualidades vocales y la articulación (Propuesta personal)

\begin{tabular}{|l|l|l|}
\hline $\begin{array}{c}\text { Cualidades de la voz y la } \\
\text { articulación vocal }\end{array}$ & \multicolumn{1}{|c|}{ Descripción } & \multicolumn{1}{c|}{ Para la articulación vocal } \\
\hline Imitaciones & $\begin{array}{l}\text { Imitamos el sonido de los animales } \\
\text { y de los elementos que nos rodean }\end{array}$ & $\begin{array}{l}\text {-Recitamos poesías } \\
\text {-Reproducimos trabalenguas } \\
\text {-Trabajamos refranes y } \\
\text { adivinanzas }\end{array}$ \\
\hline ¿Qué estoy cantando? & $\begin{array}{l}\text { Empleamos las vocales o } \\
\text { consonantes para tararear nuestra } \\
\text { canción favorita. El resto debe de } \\
\text { adivinarlo }\end{array}$ & $\begin{array}{l}\text {-Decimos las vocales de } \\
\text { forma exagerada con la boca } \\
\text {-Decimos el abecedario de } \\
\text { forma exagerada }\end{array}$ \\
\hline Los sonidos de mi voz & $\begin{array}{l}\text { Los discentes siguen las } \\
\text { instrucciones de su profesor o } \\
\text { profesora. Por ejemplo: } \\
\text { Sonidos fuertes/débiles } \\
\text { Sonidos largos/cortos } \\
\text { Sonidos agudos/graves }\end{array}$ & $\begin{array}{l}\text {-Imaginamos masticar un } \\
\text { alimento de forma exagerada } \\
\text {-Masticamos chicle al hablar } \\
\text {-Somos muditos y no } \\
\text { pronunciamos pero sí } \\
\text { articulamos palabras y } \\
\text { desciframos lo que dicen los } \\
\text { compañeros y las compañeras }\end{array}$ \\
\hline
\end{tabular}

Tabla 8. Otras actividades para las cualidades vocales (Propuesta personal)

\begin{tabular}{|l|l}
\hline \multicolumn{2}{c}{ Otras actividades para trabajar las cualidades vocales } \\
\hline Improvisación & $\begin{array}{l}\text { Dejamos unos minutos para que los niños experimenten e improvisen } \\
\text { para buscar sonidos espectaculares con su voz }\end{array}$ \\
\hline Cuento musical & $\begin{array}{l}\text { Proponemos a los niños un pequeño relato. Primero lo leen y después } \\
\text { ponen sonidos a este al mismo tiempo que el narrador lo cuenta. Para } \\
\text { ello se repartirán los personajes }\end{array}$ \\
\hline La orquesta & Simulamos ser una orquesta. Nuestra voz son instrumentos. \\
\hline
\end{tabular}

En este proyecto se hablará también de la expresión corporal, pues el trabajo con todo nuestro cuerpo es fundamental para el desarrollo de la técnica vocal. La expresión de sentimientos, emociones y la utilización del cuerpo para desinhibirnos es realmente importante.

Destaco a Cáceres Guillén (2010, p. 2) que nos define la expresión corporal como: “La disciplina cuyo objeto es la conducta motriz con finalidad expresiva, comunicativa y estética en la que el cuerpo, el movimiento y el sentimiento como instrumentos básicos”. 
Revista de Estudios en Sociedad, Artes y Gestión Cultural

www.terciocreciente.com http://revistaselectronicas.ujaen.es/index.php/RTC
Número 16

Julio 2019

Investigación

DOI: https://dx.doi.org/10.17561/rtc.

https://dx.doi.org/10.17561/rtc.n16.3

Lago González (2011-2012, p. 8-9) señala que los elementos básicos que juegan un papel crucial en la expresión corporal son el cuerpo y las emociones. Estos dos elementos como hemos visto a lo largo de este trabajo influyen en el sonido, impostación, color y timbre de la voz, pues nuestro instrumento de comunicación y expresión forma parte del cuerpo.

Según Motos (1983; citado en Sanchidrián Pose (2013, p.14)) cuando las personas nos comunicamos empleamos dos sistemas de signos, el de la palabra y el de los gestos, posturas y movimientos.

Este mismo autor (1983; citado en Sanchidrián Pose (2013, p.14)) afirma que el lenguaje corporal se relaciona con el lenguaje verbal, ya que, confirma o niega los mensajes de este. También hace que mostremos las emociones, las actitudes, el estado físico e incluso la identidad social de cada individuo.

Para trabajar la expresión corporal trabajaremos a través del juego, pues es la mejor vía para desarrollar en los niños y en las niñas cualquier tipo de aprendizaje relevante y motivador para ellos.

Cañete Pulido (2009, p.2) nos dice que la expresión corporal se refiere a:

La capacidad del cuerpo para manifestarse "como es” ante el mundo exterior con un lenguaje propio configurado por gestos, expresiones faciales, movimientos, posturas, contacto corporal y orientación y localización en el espacio.

La Expresión Corporal es una experiencia que ofrece medios para un mejor conocimiento, desarrollo y maduración del ser humano. Todo ejercicio de expresión corporal, por tanto, se convierte en una manifestación total del alumnado, ya que es necesaria la participación activa de la mente, la sensibilidad individual y la imaginación.

Para la actividad del canto es esencial trabajar los gestos, las miradas, moverse por el espacio con libertad de manera que expresemos en cada momento lo que nos dice la canción ya sea alegre, triste, con ritmos que requieran gestos y movimientos rápidos o lentos, canciones que impliquen estar más estáticos o aquellas que requieren una coreografía, etc.

La expresión corporal ayuda no solo al trabajo de la voz y de la desinhibición, sino también a mejorar la salud, ya que, como apunta Stokoe (1967; citado en Rodríguez Barquero (2008, p. 133), los objetivos específicos de esta actividad son:

- Desarrollar la sensopercepción y sensibilidad.

- Disminuir la dicotomía mente-cuerpo.

- Enriquecer la imaginación.

- Desarrollar la creatividad.

- Desarrollar el instinto investigador.

- Adquirir seguridad de sí mismo por medio de la afirmación corporal.

- Desarrollar la capacidad de aprendizaje (poder de asimilación y flexibilidad para modificar conductas) 
Recursos, metodologías y juegos para el desarrollo de la voz infantil en educación primaria https://dx.doi.org/10.17561/rtc.n16.3

- Desarrollar la capacidad de proyección y comunicación. Cultivar el goce por el juego y el sentido del humor.

- Desarrollar una actitud abierta, reflexiva, crítica y transformadora hacia la evolución propia y del prójimo.

- Observar y ser observado, criticar y ser criticado, transformar y transformarse.

- Incorporar los diversos aspectos técnicos que integran esta actividad.

Tanto para el canto como para el desarrollo de la expresión corporal es necesario realizar juegos en los que tengan que trabajar con todo su cuerpo. La autora Cañete Pulido (2009, p. 7-8) nos hace una distinción entre los siguientes tipos de juegos:

1. Juegos motores o funcionales: Son aquellos propios de los primeros años de vida e implican movimientos con todas y cada una de las partes de su cuerpo. Abarcan el periodo de 0 a 2 años. Los docentes de escuelas preescolares o guarderías deben de considerar estos juegos que propone la autora. (Juegos con su cuerpo, juegos con desplazamientos, juegos con objetos, juegos de interacción social).

2. Juegos simbólicos o de ficción: aquellos que son espontáneos y que en sí mismos no tienen ninguna finalidad aparente, donde los niños y la niñas asumen funciones de determinados roles realizando acciones "ficticias" como si fueran reales. También se incluyen los juegos de imitación de expresión de estados de ánimo y emociones.

3. Juegos dramáticos: actividades en donde el grupo de niños y niñas inventa e improvisa a partir de temas y personajes elegidos por ellos mismos, sin la presencia de espectadores y donde todos juegan simultáneamente. Se inicia cuando aparece la función simbólica. (Juegos de expresión corporal, mimodrama o pantomima, dramatización de historias, teatro de títeres o marionetas, etc.)

Según Arguedas Quesada (2004, p. 124), la expresión corporal y la música están íntimamente relacionadas porque:

En las clases de expresión corporal, la música sirve como elemento de apoyo, para que los infantes disfruten y muestren sus diferentes estados de ánimo; además les ayuda a conseguir una mejor comunicación. En estas sesiones, no puede faltar el placer del movimiento y el sentido lúdico, se liberan energías y se orientan hacia la expresión del ser. Por esta razón, su finalidad es contribuir a la integración de la persona, donde el cuerpo traduce el estado anímico del individuo, por medio de gestos, movimientos o quietud del cuerpo, con mensajes silenciosos o sonoros, individuales o colectivos.

También esta autora (2004, p. 124) afirma que:

La educación del movimiento traduce en el espacio, mediante la acción, los ritmos percibidos a través del oído, es decir, se coordinan los movimientos y las actitudes de los estudiantes con el estímulo sonoro.

Por ello, un acompañamiento rítmico melódico como fondo de cualquier ejercicio, favorece la realización de este. El alumno recrea con el movimiento los ritmos, tempos o matices musicales que escucha, a la vez que desbloquea sus 
propias potencialidades expresivas, explorando las posibilidades de improvisación y de creación.

A continuación, muestro una tabla en la que recojo algunos juegos que he trabajado a lo largo de mis estudios en el grado de Infantil, Primaria y durante el Máster de Investigación en Artes, Música y Educación Estética (2015/2016), también hay otras propuestas totalmente personales. Todos están destinados a la expresión corporal:

Tabla 9. Actividades para expresión corporal y canto (Propuesta personal)

\begin{tabular}{|c|c|}
\hline \multicolumn{2}{|r|}{ ACTIVIDADES } \\
\hline Nombre del juego & Descripción \\
\hline ¿Cómo me siento? & $\begin{array}{l}\text { Realizamos equipos de } 6 \text { alumnos y alumnas } \\
\text { aproximadamente, cada equipo piensa en una emoción o en } \\
\text { un sentimiento. (Para Infantil, les damos imágenes y ellos } \\
\text { tienen que imitarlas). Seguidamente, les damos un tiempo } \\
\text { para pensar cómo hacerlo. Después, un grupo lleva a cabo } \\
\text { las acciones pertinentes (teniendo en cuenta que deben de } \\
\text { emitir sonidos, realizar gestos o movimientos pero no } \\
\text { pueden pronunciar palabras); el resto del grupo debe de } \\
\text { adivinar qué emoción o sentimiento se esconde detrás de } \\
\text { todo ello. }\end{array}$ \\
\hline ¿Qué veo en el cine? & $\begin{array}{l}\text { Por grupos piensan una peli que les gusten, deben de } \\
\text { interpretar una escena de esta pero cantando la canción } \\
\text { correspondiente a la película. (Podemos mostrarle escenas } \\
\text { de las películas más conocidas por ellos y que partan de una } \\
\text { de ellas, e incluso buscar las canciones pertinentes de cada } \\
\text { escena y ponerlas en el aula para escucharlas y cantarlas } \\
\text { todos juntos). También en vez de cantar podemos pedirle } \\
\text { para complicarlo un poco más que en vez de cantar solo } \\
\text { tararen. }\end{array}$ \\
\hline Al son de la canción & $\begin{array}{l}\text { Por grupos repartimos la letra de las canciones más } \\
\text { conocidas o trabajadas en clase por los niños y las niñas, les } \\
\text { pedimos que la interpreten y las canten pero cambiando la } \\
\text { letra de la canción, cambiando gestos o incluso estados de } \\
\text { ánimo. (Esta actividad solo para Primaria). En Infantil } \\
\text { reproducimos las canciones que hemos trabajado y al pararla } \\
\text { deben de seguir cantando y haciendo los movimientos y } \\
\text { gestos aprendidos. }\end{array}$ \\
\hline Vocaliemoción & $\begin{array}{l}\text { Para este juego los alumnos y las alumnas se agrupan según } \\
\text { la última vocal de su nombre. Para ello caminan por el } \\
\text { espacio diciendo dicha vocal hasta que todos estén } \\
\text { agrupados. Después deben de pensar en una emoción que } \\
\text { contenga dicha vocal, una vez pensada empiezan a tararear } \\
\text { una canción solo con dicha vocal pero expresando la } \\
\text { emoción que ha elegido. El resto de los grupos deben de }\end{array}$ \\
\hline
\end{tabular}




\begin{tabular}{|c|c|}
\hline & $\begin{array}{l}\text { adivinar la emoción y la canción que interpretan. (Esta } \\
\text { actividad está más indicada para Primaria). En Infantil } \\
\text { podemos hacer lo mismo, que se agrupen y que con dicha } \\
\text { vocal tararen una canción de las trabajadas en clase o de sus } \\
\text { dibujos preferidos. }\end{array}$ \\
\hline El espejo sonoro & $\begin{array}{l}\text { Todos los alumnos y las alumnas corren por el espacio, en } \\
\text { un momento determinado el profesor o la profesora toca a un } \\
\text { compañero o compañera, este o esta dice su nombre y realiza } \\
\text { un gesto, el resto de los compañeros y compañeras lo imitan. }\end{array}$ \\
\hline El pañuelo de las emociones & $\begin{array}{l}\text { Distribuimos en dos grupos a los alumnos y a las alumnas, a } \\
\text { cada uno en vez de números les asignamos una emoción. Al } \\
\text { decir la emoción salen en busca del pañuelo para llevarlo a } \\
\text { su terreno de juego, antes de coger el pañuelo debe de repetir } \\
\text { el nombre de la emoción según las indicaciones del maestro } \\
\text { que sostiene el pañuelo (fuerte, suave, despacio, rápido, } \\
\text { largo, corto...) }\end{array}$ \\
\hline Exploramos nuestro cuerpo & $\begin{array}{l}\text { Este juego consiste en ir bailando al ritmo de una música por } \\
\text { el espacio. Cuando la música se pare deberán de fijar una } \\
\text { postura y unos gestos con su cuerpo (no se puede repetir). } \\
\text { En un momento determinado al parar la música y al quedar } \\
\text { en estatuas se les piden que tararen un trozo de la canción } \\
\text { que han escuchado. }\end{array}$ \\
\hline Nuestros tesoros más preciados & $\begin{array}{l}\text { Pedimos a cada alumno y a cada alumna que traigan a clase } \\
\text { una caja en donde se encuentren sus objetos más preciados. } \\
\text { Una vez allí cada uno coloca sus cajas encima de su mesa. } \\
\text { La maestra va preguntando a uno por uno qué han traído y } \\
\text { por qué son importantes para ellos. Y les pide que escriba la } \\
\text { emoción que le despierta ese objeto. Así se despertarán } \\
\text { diferentes emociones. Después, todos veremos las cajas de } \\
\text { todos y en conjunto reflexionaremos sobre lo que hemos } \\
\text { sentido, cómo cambiaba la cara cuando estábamos tristes o } \\
\text { alegres, cómo hemos manifestado lo que sentíamos, etc. }\end{array}$ \\
\hline Karaoke en clase & $\begin{array}{l}\text { Vamos a jugar al karaoke. Montamos en clase un escenario. } \\
\text { Todos los niños son el público. Cada vez que suena una } \\
\text { música irá apareciendo la letra de la canción en pantalla. } \\
\text { Todos los niños comenzarán a cantar. En el momento que la } \\
\text { profesora diga el nombre de un alumno o de una alumna, el } \\
\text { resto se calla para que este continúe. Después dirá itodos! Y } \\
\text { volverán a cantar todos a la vez. Trabajaremos con } \\
\text { canciones adaptadas a su tesitura vocal y no solo en español. } \\
\text { Podemos incluir variantes como: una canción alegre cantarla } \\
\text { con alegría o al contrario, añadir gestos, posturas, etc. Luego } \\
\text { se reflexionarán en grupo sobre ello. }\end{array}$ \\
\hline
\end{tabular}


https://dx.doi.org/10.17561/rtc.n16.3

\begin{tabular}{|l|l|}
$\begin{array}{l}\text { Conozco a mis compañeros y } \\
\text { compañeras }\end{array}$ & $\begin{array}{l}\text { Al azar cada niño y niña cogerá un papelito de una caja. En } \\
\text { este van a encontrar el nombre de un compañero o de una } \\
\text { compañera de clase. Deberá escribir tres aspectos positivos y } \\
\text { tres aspectos que puede mejorar. También anotará algo que } \\
\text { identifique a dicho compañero y lo haga especial. (Para } \\
\text { Infantil lo hacemos de forma oral si no se puede por escrito) }\end{array}$ \\
\hline Los colores de mi cuerpo & $\begin{array}{l}\text { Para este juego necesitamos pinturas de cara de colores } \\
\text { diferentes. Se hace un punto de cada color en diferentes } \\
\text { partes de nuestro cuerpo. Cuando se diga un color, los niños } \\
\text { y las niñas deberán tocar el punto que corresponda y realizar } \\
\text { un gesto para identificar dicho color. }\end{array}$ \\
\hline
\end{tabular}

A diferencia del tema de la técnica vocal, este existen multitud de fuentes bibliográficas dedicadas al estudio del repertorio escolar. Es un asunto que sí ha sido y es muy estudiado en la actualidad por grandes profesionales debido a su relevancia, a su utilización diaria en las distintas áreas de conocimiento para fines diversos y de forma específica en música.

El repertorio escolar es un aspecto muy debatido por muchos especialistas, ya que se ha intentado llegar a un acuerdo sobre cuál es el más indicado para las voces infantiles y qué utilidad tiene este en nuestras aulas.

Entre las fuentes bibliográficas destaco a Bernal y Calvo (2004, p. 48) que dicen que la canción escolar es "la actividad musical escolar más importante, en ella se engloban una serie de aspectos como sensibilidad, afectividad, ritmo y educación tonal, de ahi la importancia de seleccionar un repertorio adecuado".

Cámara Izagirre (2003, p. 106) dice que:

El niño disfruta cantando porque cantar es jugar, es una actividad social que permite reafirmarse y reencontrarse a sí mismo al escucharse y mostrarse a los demás cuando le escuchan, es gozar de la materia musical a través de la cual se expresa y del significado del texto que lo acompaña, es un instrumento para adquirir diferentes habilidades.

Barrera Benjumea (2010) señala tres tipos de metodologías para trabajar el repertorio escolar y que se han tenido en cuenta en este trabajo (imitativa, intermedia y lectoescritura), además tiene cuenta las aportaciones de Crivillé y realiza un estudio para clasificar las canciones escolares según los ciclos de vida (infancia, adolescencia, adultos...) y las estaciones del año.

El pedagogo musical Willems (1976: 53 - 54) también estudia el repertorio escolar y realiza una clasificación más escueta sobre este. De Mena (1994) trata este tema aportando ideas muy importantes para la elección del repertorio, así como los pasos a seguir para su aprendizaje e interiorización.

Cabrera Padilla (2012, p. 36-39) que nos enumera y explica de forma clara y concisa los diferentes beneficios que nos aporta la actividad del canto, estos en palabras de dicha autora son: Los beneficios físicos, beneficios psicológicos, beneficio intelectual y beneficio creativo. 
El pedagogo musical Willems (1976: 53 - 54) clasifica las canciones escolares en cinco tipos (véase tabla 11).

Tabla 11. Canciones escolares según Willems (1976: 53 - 54)

\begin{tabular}{|l|l|}
\hline Canciones populares & $\begin{array}{l}\text { Canciones Escolares } \\
\text { hogares }\end{array}$ \\
\hline $\begin{array}{l}\text { Canciones sencillas para } \\
\text { principiantes }\end{array}$ & $\begin{array}{l}\text { Son canciones simples de interiorizar mediante la } \\
\text { escucha activa }\end{array}$ \\
\hline Canciones instrumentales & Canciones para acompanar con instrumentos musicales \\
\hline Canciones de intervalos & Comenzando por la segunda mayor \\
\hline Canciones mimadas & $\begin{array}{l}\text { Su objetivo es que se produzca una conexión entre el } \\
\text { sentido de las palabras y la mímica y las canciones } \\
\text { ritmadas con el fin de desarrollar el instinto del ritmo } \\
\text { musical y basada en el movimiento natural del cuerpo }\end{array}$ \\
\hline
\end{tabular}

Los docentes debemos de seguir unos criterios para la elección del repertorio escolar, de esta forma evitaremos problemas vocales, escasa participación y la desmotivación hacia el canto: (véase cuadro 3):

\section{Cuadro 3. Criterios para elegir una canción en Primaria}

\section{Criterios para seleccionar una canción para educación Primaria}

Los compases más empleados son el binario, el cuaternario. De las canciones andaluzas son de compás ternario

Primer ciclo de Primaria habría que emplear el canto monódico (una sola línea melódica) y homofónico (varias voces cantan con una misma línea melódica).Y acompañamientos sencillos

Segundo ciclo se introduce el canto polifónico (cantan varias voces y hay varias líneas melódicas). Se pueden trabajar cánones a dos y tres voces (es una composición polifónica en la cual las voces se introducen de forma sucesiva y cada voz imita a la anterior) y acompañamientos

En relación a la metodología que se puede emplear para el aprendizaje y la memorización de una canción en Primaria, la autora $\mathrm{M}^{\mathrm{a}}$ del Carmen Barrera (2010) señala tres tipos de metodologías: 
https://dx.doi.org/10.17561/rtc.n16.3

1) Metodología imitativa: consiste en trabajar mediante la imitación. La canción es aprendida y memorizada de oído. Esta metodología es ideal para el primer ciclo de Primaria. El proceso de aprendizaje queda explícito en la siguiente tabla (véase tabla 12):

Tabla 12. Proceso de una metodología imitativa

\begin{tabular}{|l|l|}
\hline \multicolumn{1}{|c|}{ Pasos } & \multicolumn{1}{|c|}{ Descripción } \\
\hline Recitamos el texto & $\begin{array}{l}\text { No se entona ni se hace con ritmo. Esto se repetirá varias veces pero } \\
\text { jugando con los discentes, dramatizándolo, con buena articulación } \\
\text { etc. }\end{array}$ \\
\hline Ritmo & $\begin{array}{l}\text { Cuando se hayan familiarizado con el texto, se incorpora el ritmo de } \\
\text { la canción. }\end{array}$ \\
\hline $\begin{array}{l}\text { La melodía se trabaja por } \\
\text { partes }\end{array}$ & $\begin{array}{l}\text { Emplear una sílaba para cada palabra o frase. Se utilizan sílabas } \\
\text { directas, de "consonante - vocal". Podemos trabajar con las cinco } \\
\text { vocales. } \\
\text { Se empieza a utilizar las sílabas con la forma "vocal+consonante". } \\
\text { Se trabaja la forma "consonante+vocal+consonante" } \\
\text { Se emplean consortes intermedias y al final: } \\
\text { "consonante+consonante+vocal" } \\
\text { Al final consonantes intermedias y } \\
\text { "consonante+consonante+vocal+consonante" }\end{array}$ \\
\hline Letra real de la canción & $\begin{array}{l}\text { Cuando aprendan la canción, añadimos la letra real de esta y se } \\
\text { cantan varias veces. Podemos realizar los siguientes ejercicios: } \\
\text { Trabajamos los gestos faciales y de todo el cuerpo } \\
\text { Hacemos ejercicios de interiorización y de expresión rítmica } \\
\text { Jugamos con las partes del textos (cambio de orden o suprimiendo } \\
\text { partes) } \\
\text { Pensamos en la letra y la trabajamos. Vemos las partes de la canción } \\
\text { y las estudiamos } \\
\text { Interpretamos el texto } \\
\text { Incorporamos baile etc. }\end{array}$ \\
\hline $\begin{array}{l}\text { Que cada uno siga la melodía cómo prefiera. Con esta metodología } \\
\text { trabajamos el lenguaje oral }\end{array}$ \\
\hline Improvisación
\end{tabular}

2) Metodología intermedia: empleamos la metodología imitativa pero incorporando ayudas visuales, gráficas, de pre-escritura, gestuales etc. Esta metodología también la podemos emplear en los tres ciclos de Primaria.

Se emplea la escritura no convencional (ejemplo: musicogramas). También percusión corporal. Pueden hacer dibujos gráficos del ritmo, de la entonación etc.

3) Metodología de lecto - escritura: se trabaja mediante la lecto-escritura musical convencional. Se emplea el segundo y tercer ciclo. El proceso para trabajar la canción sería siempre por partes o compases y los podemos ver en la tabla (véase tabla 13):

Tabla 13. Proceso de una metodología de lecto - escritura

\begin{tabular}{|c|c|}
\hline \multicolumn{1}{|c|}{ Pasos } & \multicolumn{1}{c|}{ Descripción } \\
\hline Se lee el texto y se trabaja con las & Se trabaja sin ritmo y sin entonación \\
\hline
\end{tabular}




\begin{tabular}{|l|l|}
\hline cualidades de sonido & \\
\hline Se lee el texto pero trabajando el ritmo & Lectura con percusión corporal. Lectura de las figuras \\
& de las notas \\
& Lectura a través de una sílaba \\
& Ejercicios de ritmo y para reconocer las notas de \\
& pentagrama \\
& Se añade el texto \\
\hline Entonación & Se entonan las notas \\
\hline Ritmo y entonación & Se añade el ritmo a la entonación \\
\hline Texto, ritmo, entonación & Se vuelve a añadir el texto \\
\hline
\end{tabular}

Estos pasos deben ser tenidos en cuenta a la hora de enseñar una canción dentro del aula, pues he comprobado que realmente funciona.

\section{FASE 2: OBSERVACIÓN EN EL AULA}

Las clases de $3^{\circ}$ de Primaria son amplias, las mesas son movibles por lo que también las podemos colocar para trabajar en grupos. Las clases están muy bien iluminadas. Por lo general todo está muy bien organizado y colocado para que no interrumpa el acceso a los discentes y profesores y para que sea cómo acceder a ellos.

Los alumnos y alumnas de $3^{\circ}$ de Primaria tienen clase de artística (plástica y música) una hora por lo que cada semana se da una de las dos disciplinas o se le dedica media hora a cada uno. Todo depende de cómo estén planeadas las sesiones.

Mi proyecto lo llevé a cabo en el segundo ciclo de Primaria y concretamente en la clase de $3^{\circ}$ de Primaria A y B. En $3^{\circ}$ A hay 12 alumnos y 14 alumnas, en total hay 26 alumnos. En $3^{\circ} \mathrm{B}$ hay 10 alumnos y 15 alumnas, en total hay 25 alumnos. Entre los dos $3^{\circ}$ hay 51 . Todos los alumnos y las alumnas independientemente de sus características peculiares llevan el mismo ritmo de trabajo. Normalmente trabajamos en grupos heterogéneos y de forma cooperativa porque los resultados son más favorables y los alumnos y las alumnas se sienten más motivados. Pese a esto también habrá tareas individuales.

Todos los discentes se muestran muy activos y participativos en sus clases, a excepción de alguno que le cuesta más trabajo tener iniciativas y participar pero conforme se desarrolla la clase se va animando e incorporando. El clima de trabajo y de cooperación en el aula es muy favorable. Mis niños y mis niñas respetan las normas para mantener el silencio, la disciplina, los turnos de palabra y el orden en las clases.

Además no hay conflictos, por ello la convivencia es estupenda y todos son compañeros de todos. Por lo general hay material suficiente para hacer unas clases de música significativas, amenas y divertidas. Además las profesoras traemos materiales que no están en clase y que serán imprescindibles para desarrollar las sesiones.

\section{FASE 3: PROCESO DE PREPARACIÓN DE LA UNIDAD DIDÁCTICA "LA BRUJITA TAPITA"}

Para justificar mi proyecto voy a empezar diciendo que "las voces son un tesoro para los humanos porque gracias a ellas nos comunicamos, expresamos sentimientos y emociones y cantamos y con ella y los instrumentos musicales creamos lo que llamamos música”. El título de mi propuesta es Pequeños relatos para sentir la música desde el corazón, esta tiene 
como fin conseguir que mis queridos alumnos y mis alumnas adquieran saberes y valores para un aprendizaje significativo, ameno, desde la experiencia, desde el corazón y sobre todo duradero.

Todo el proyecto está formado por quince unidades didácticas que se desarrollarán a lo largo de los tres trimestres durante las horas de clases. La temática que vamos a trabajar, los contenidos musicales y la metodología empleada es ideal y adaptada para mis alumnos y alumnas de entre 8 y 9 años. Para la adecuación de los elementos curriculares a mi propuesta anual he consultado y analizado la normativa vigente (LOMCE y Real Decreto 126/2014, de 28 de febrero, por el que se establece el currículo básico de la Educación Primaria).

El hilo conductor de mi propuesta es un personaje ficticio que aparecerá como narradora de todos los relatos empleados a lo largo de este curso, esta es la abuelita Manuelita y estará representada por un títere, que llevaremos cada día a clase para que cuente las historias. Cada unidad didáctica empieza a desarrollarse a partir de los relatos de la abuela Manuelita.

He utilizado la lectura porque en este ciclo es imprescindible trabajar la comprensión y expresión oral y escrita y porque es una manera divertida de introducir cada unidad didáctica porque ayuda a los discentes a tener una idea de lo que van a trabajar. Además hay célebres autores que apuntan que la lectura es necesaria e imprescindible para la vida de los niños y de las niñas.

Por ejemplo: Fernando Trueba dice que: "La lectura es placer, conocimiento, emoción, enajenación", Miguel de Cervantes deja claro que "El que lee mucho y anda mucho, ve mucho y sabe mucho", Mario Vargas Llosa explica que "Aprender a leer es lo más importante que me ha pasado en la vida" y por último, J.L. Borges defiende la idea de que "De los diversos instrumentos inventados por el hombre, el más asombroso es el libro; de todos los demás son extensiones de su cuerpo... Sólo el libro es una extensión de la imaginación y la memoria".

Yo pienso de la misma forma que estos y otros muchos escritores por eso en todos mis planning anuales o proyectos introduzco la lectura. A mis alumnos y alumnas de $3^{\circ}$ de Primaria les encanta leer y se divierten con ella por eso sé que esta forma de trabajar va a funcionar. En todas las áreas utilizo la lectura y va muy bien.

Los relatos que se van a leer en clase serán inventados y escritos por mí misma para que sean un inicio de lo que se va a aprender en las clases. Además todas las fichas de trabajo, audiciones, coreografía etc., serán creados por mí misma pensando siempre en mis alumnos y en mis alumnas.

En este planning está subrayada la transdisciplinariedad entre las distintas áreas de conocimiento. También se trabajarán valores éticos, valores sociales y contenidos de las distintas áreas de conocimiento pero sobre todo se enseñarán conocimientos musicales. Trabajaremos mediante grupos cooperativos, trabajo individual y trabajo en gran grupo.

Tabla 14. Unidades Didácticas de $3^{\circ}$ de Primaria A y B

\begin{tabular}{|c|c|c|c|}
\hline \multicolumn{4}{|c|}{ Pequeños relatos para sentir la música desde el corazón } \\
\hline \multicolumn{4}{|c|}{ PRIMER TRIMESTRE } \\
\hline SEPTIEMBRE & OCTUBRE & NOVIEMBRE & DICIEMBRE \\
\hline $\begin{array}{l}\quad \text { Unidad didáctica I: } \\
\quad \text { “Hola compañeros!” } \\
\text { Juegos de socialización } \\
\text { Audiciones para reconocer } \\
\text { Percusión corporal } \\
\text { Voz: respiración, } \\
\text { calentamiento, repasamos una } \\
\text { canción del curso anterior } \\
\text { (Hay un amigo en mi de la }\end{array}$ & $\begin{array}{l}\text { Unidad didáctica II: } \\
\text { “ Conocemos a la abuelita } \\
\text { Manuelita” } \\
\text { La abuela Manuelita (relato) } \\
\text { Canción: Mi abuela } \\
\text { Manuelita } \\
\text { Identificamos los sonidos } \\
\text { do, mi, sol, do' } \\
\text { El pentagrama }\end{array}$ & $\begin{array}{l}\text { Unidad didáctica IV: } \\
\text { "Viajamos a Bosque- } \\
\text { sustos" } \\
\text { Sonidos de la naturaleza } \\
\text { Sonidos fuertes y suaves } \\
\text { Sonidos largos y cortos. } \\
\text { Musicograma } \\
\text { Voz: Juguemos en el } \\
\text { bosque }\end{array}$ & $\begin{array}{l}\text { Unidad didáctica V: } \\
\text { "Aventura por Navidad" } \\
\text { Instrumentos musicales } \\
\text { navideños } \\
\text { Sonidos largos y cortos } \\
\text { Negra, silencio de negra } \\
\text { y corcheas } \\
\text { Compás binario } \\
\text { Voz: Oye San Nicolás de }\end{array}$ \\
\hline
\end{tabular}




\begin{tabular}{|c|c|c|c|}
\hline $\begin{array}{l}\text { película de Toy Story) y } \\
\text { relajación. } \\
\text { Dibujo de lo mejor de la } \\
\text { sesión. } \\
\text { Canción: } \\
\text { https://www.youtube.com/wat } \\
\text { ch?v=-nXuidFvygk }\end{array}$ & $\begin{array}{l}\text { La clave de sol } \\
\text { Negra y su silencio } \\
\text { Ritmo binario } \\
\text { Percusión corporal } \\
\text { Voz: La abuelita Manuelita } \\
\quad \text { Unidad didáctica III: } \\
\text { “Aventura en Anima-canta" } \\
\text { Sonidos animales } \\
\text { Sonidos graves y agudos } \\
\text { Imitación de animales } \\
\text { Negra y silencio de negra } \\
\text { Voz: La marcha de mi tía } \\
\text { Clementina } \\
\text { Canción } \\
\text { https://www.youtube.com/w } \\
\text { atch?v=P1OcVirjVSI }\end{array}$ & $\begin{array}{l}\text { Canción: } \\
\text { https://www.youtube.com/ } \\
\frac{\text { watch?v=uQ01V9QGKBY }}{\text { Unidad didáctica V: }} \\
\text { “Aventura por Navidad” } \\
\text { Instrumentos musicales } \\
\text { navideños } \\
\text { Sonidos largos y cortos } \\
\text { Negra, silencio de negra y } \\
\text { corcheas } \\
\text { Compás binario } \\
\text { Musicograma } \\
\text { Voz: Oye San Nicolás de } \\
\text { la película (Barbie en un } \\
\text { cuento de Navidad). } \\
\text { Villancico: } \\
\text { https://www.youtube.com/ } \\
\text { watch?v=xa2no0npvFA }\end{array}$ & $\begin{array}{l}\text { la película de Barbie en } \\
\text { un cuento de Navidad } \\
\text { Villancico: } \\
\text { https://www.youtube.co } \\
\underline{\mathrm{m} / \mathrm{watch} \text { ? }=\mathrm{xa} 2 \mathrm{no0npvF}} \\
\underline{\mathrm{A}}\end{array}$ \\
\hline
\end{tabular}

\begin{tabular}{|c|c|c|c|}
\hline \multicolumn{4}{|c|}{ Pequeños relatos para sentir la música desde el corazón } \\
\hline \multicolumn{4}{|c|}{ SEGUNDO Y TERCER TRIMESTRE } \\
\hline ENERO & FEBRERO & MARZO & ABRIL \\
\hline Unidad didáctica VI: & Unidad didáctica VIII & Unidad didáctica IX & Unidad didáctica XI \\
\hline “¿Dónde están las emociones?” & Nos encontramos con & “Los lunares del vestido & “TRATATÁN TAN \\
\hline Audición: estados de ánimo & Mozart y Beethoven, & de la abuela Manuelita " & TAN" \\
\hline Sonidos graves y agudos & ¡Qué "GUAY”! & Sonidos corporales & Bandas de \\
\hline voces femeninas, masculinas e & Obras clásicas & Castañuelas & SEMANA SANTA \\
\hline infantiles & instrumentales y vocales & Percusión corporal & Percusión corporal \\
\hline Voz: Despacio me tranquilizo y & Sonidos graves y agudos & Bailamos y cantamos una & Negra, silencio de \\
\hline Corazones amigos & Tipos de voces & sevillana para luego & negra, corchea y \\
\hline Canciones & Algunos instrumentos & llevarla a cabo en el salón & blanca. \\
\hline Despacito me tranquilizo & clásicos & de actos para que lo vean & Onomatopeyas de \\
\hline https://www.youtube.com/watch?v=Zal & - MOZART Y & los familiares. & instrumentos de \\
\hline rQFAT5W0\&list=PL8Qpve81cSHPwL & BEETHOVEN (Para & Voz: Yo soy del sur & Semana Santa. \\
\hline 6cHjD3H45cjDZU z8yp & Elisa) & Sevillana & Voz: recitamos la \\
\hline Corazones amigos & - Vemos dos capítulos de & https://www.youtube.com/ & de Antonio \\
\hline https://www.youtube.com/watch?v=US & LA BANDA DE & watch?v=7MWwXtYkON & Machado "La saeta". \\
\hline qbZiPrOdU\&index=3\&list=PL8Qpve8 & MOZART (La flauta & & Poema \\
\hline 1cSHPwL6cHjD3H45cjDZU z8yp & mágica). Hacemos un & Unidad didáctica $X$ & http://www.poemas- \\
\hline $\begin{array}{c}\text { Unidad didáctica VII: } \\
\text { "Qué veo en un musical?" }\end{array}$ & $\begin{array}{l}\text { trabajo de investigación } \\
\text { sobre ellos en grupo. }\end{array}$ & $\begin{array}{c}\text { "Abuelo, abuelito ¿Existe } \\
\text { el silencio?”" }\end{array}$ & $\frac{\text { del-alma.com/la- }}{\text { saeta.htm }}$ \\
\hline Visionado de un musical (La Sirenita) & 1. BEETHOVEN: PARA & Diferencia entre ruido & http://www.poesi.as/ \\
\hline Musical: & ELISA Capítulo 3 & silencio & amach130.htm \\
\hline https://www.youtube.com/watch?v=1v & https://www.youtube.co & Vemos en clase la obra de & https://www.youtube \\
\hline mrY12VF1c & $\underline{\mathrm{m} / \mathrm{watch} ? \mathrm{v}=\mathrm{dFJCqMsO}}$ & John Cage de 4'33" & $. \mathrm{com} / \mathrm{watch} ? \mathrm{v}=\mathrm{ueDc}$ \\
\hline$\overline{\text { Identificar personajes }}$ & $\mathrm{HbU}$ & ¿Qué escuchamos en el & m9LmNZo \\
\hline Imitación de personajes del musical. & MOZART: LA & silencio? & 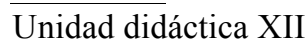 \\
\hline Improvisación & FLAUTA MÁGICA & https://www.youtube.com/ & "E1 libro tramposo" \\
\hline Voz: Bajo el mar de la sirenita & https://www.youtube.co & watch?v=zY7UK-6aaNA & Tocamos la flauta \\
\hline https://www.youtube.com/watch?v=I & m/watch?v=LZNbInMM & Conocemos la flauta & mi, sol y la (libro de \\
\hline xDgZVenJ8 (lo representamos en el & HAI & (experimentamos con ella) & música) \\
\hline salón de actos, simulamos nuestro & 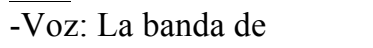 & Aprendemos sol y mi con & Poesía \\
\hline propio musical de una parte de la & Mozart opening. & la flauta (libro de música) & Adivinanzas \\
\hline$\underline{\text { Sirenita) }}$ & Canción: & Voz: Si yo fuera silencio & Retahíla \\
\hline Canción: & La banda de Mozart & Con musicograma & Trabalenguas \\
\hline $\begin{array}{l}\text { Asistimos al musical del Rey León en } \\
\text { Madrid }\left(3^{\circ} \mathrm{y} 4^{\circ}\right)\end{array}$ & $\begin{array}{l}\frac{\text { https://www.youtube.co }}{\mathrm{m} / \mathrm{watch} ? \mathrm{v}=\mathrm{tMjGvDZ6w}} \\
\mathrm{jw}\end{array}$ & $\frac{\text { https://www.youtube.com/ }}{\text { watch?v=OZFAedNij1M }}$ & $\begin{array}{l}\text { Voz: En el bosque de } \\
\text { la china. } \\
\text { Canción } \\
\text { https:/www voutube }\end{array}$ \\
\hline
\end{tabular}




\begin{tabular}{|c|c|}
\hline \multicolumn{2}{|c|}{ Pequeños relatos para sentir la música desde el corazón } \\
\hline \multicolumn{2}{|c|}{ TERCER TRIMESTRE } \\
\hline MAYO & JUNIO \\
\hline $\begin{array}{l}\text { Unidad didáctica XIII } \\
\text { "Instrumenti” } \\
\text { Sonidos de instrumentos (piano, violín, guitarra, flauta } \\
\text { dulce, trompeta y tambor) } \\
\text {-Sonidos graves y agudos } \\
\text {-Sonidos fuertes y suaves } \\
\text { Tocamos la flauta (mi, sol, la), libro de música } \\
\text { Creamos un instrumento con reciclaje y le hacemos sonar } \\
\text { Voz: “Los alambres del teléfono”. } \\
\text { Canción: } \\
\text { https://www.youtube.com/watch?v=_OA6tX6H7b8 } \\
\quad \text { Unidad didáctica XIV } \\
\quad \text { Relato final } \\
\text { Canción: La brujita Tapita (para fin de curso) } \\
\text { Percusión corporal } \\
\text { Memorizamos la letra, la ponemos en escenas y nos } \\
\text { disfrazamos } \\
\text { Actividades sobre la canción } \\
\text { CANCIÓN LA BRUJITA TAPITA: } \\
\text { https://www.youtube.com/watch?v=XTpWPVXIRFE }\end{array}$ & $\begin{array}{l}\text { Unidad XV: } \\
\text { “iLlegan las vaca- vacaciones!” } \\
\text { ¿A dónde viajamos? (todos elegimos dos destinos para } \\
\text { pasar las vacaciones allí ¿qué música se escuchan? } \\
\text { ¿Cómo son sus bailes? } \\
\text { BAILE: CHACHACHA } \\
\text { SE LO ENSEÑAMOS A 2o PRIMARIA } \\
\text { https://www.youtube.com/watch?v=QcRP5mijEII } \\
\text { Voz: La brujita tapita" } \\
\frac{\text { https://www.youtube.com/watch?v=XTpWPVXIRFE }}{\text { ¡FIESTA FINAL! }}\end{array}$ \\
\hline
\end{tabular}

De todas las que presento en la tabla anterior voy a desarrollar en este trabajo la unidad didáctica Unidad didáctica XIV titulada: “¡Mirad la bruja Tapita!”.

En esta unidad la abuelita presenta a la protagonista y cuenta las aventuras de la Brujita Tapita. Esta unidad lleva este nombre porque la historia de introducción se llama así, porque la canción que los niños van a trabajar lleva ese mismo nombre y porque a mis alumnos y alumnas les encantan las historias divertidas. Además vamos a trabajar contenidos musicales que se van a relacionar con aspectos que van a aparecer en el relato pero sobre todo vamos a desarrollar de manera especial la voz. Trabajaremos una canción llamada La bruja Tapita, también bailaremos además de cantar, crearemos una coreografía apropiada y nos disfrazaremos de brujitas y brujitos.

Según la normativa vigente Real Decreto 126/2014, de 28 de febrero, por el que se establece el currículo básico de la Educación Primaria. Cada unidad didáctica debe de conseguir que el alumnado adquiera mediante la consecución de unas competencias básicas interiorizar una serie de contenidos musicales y de valores personales y sociales para poder llegar a los objetivos que se marcan para cada unidad. De forma específica en esta unidad didáctica vamos a reforzar y a desarrollar las siguientes competencias:

1. ' Comunicación lingüística: en todas las clases los alumnos y las alumnas deberán de leer el relato, realizar una comprensión lectora oral, deducir las ideas principales, diferenciar a los personas protagonistas de los secundarios, reconocer el planteamiento, el nudo y el desenlace etc. En ocasiones las preguntas de comprensión se realizarán en una ficha por escrito. Para 


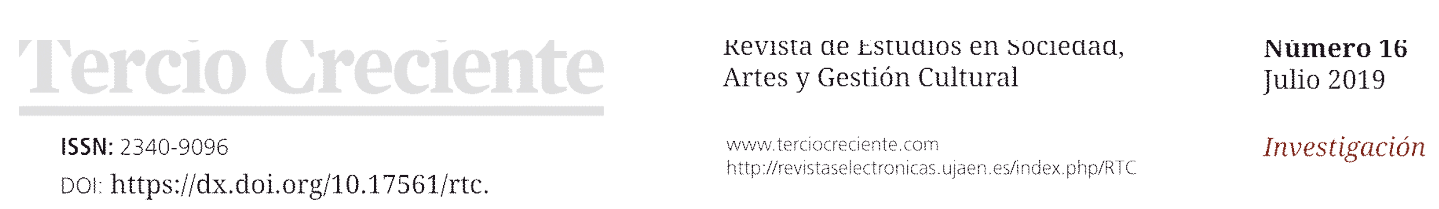

https://dx.doi.org/10.17561/rtc.n16.3

estudiar la canción leemos y trabajamos la letra de esta y hablamos de ella en clase. Por supuesto en clase se realizarán reflexiones sobre lo aprendido cada día.

4. ${ }^{\circ}$ Aprender a aprender: Mis alumnos y mis alumnas van a trabajar de forma autónoma, van a adquirir conocimientos y actitudes que les van a permitir seguir aprendiendo y superándose en cada sesión. En cada sesión tendrán que reflexionar sobre lo aprendido y valorar su trabajo y el de sus compañeros, darán sus puntos de vista en clase. Tendrán que ser responsables con su trabajo diario para obtener buenos resultados. Es importantísima su participación en todo momento y $\mathrm{s}$ eles dará la oportunidad para que desarrollen su creatividad e imaginación.

5. ${ }^{\circ}$ Competencias sociales y cívicas: con esta unidad didáctica los alumnos se relacionan entre ellos y se comunican, además cantan, bailan y se divierten juntos. Se refuerzan los lazos afectivos en cada una de las actividades en grupo, comparten sentimientos, experiencias y emociones, aprenden unos valores importantísimos para convivir los unos con los otros como tolerancia, respeto a los demás, empatía, libertad de expresión, generosidad etc.

Todos deben de obedecer unas normas de convivencia para que el clima de trabajo sea apropiado. Además se emplea el aprendizaje cooperativo en el que cada integrante del grupo tiene un rol que cumplir.

6. 'Sentido de iniciativa y espíritu emprendedor: Esta competencia está íntimamente relacionada la de aprender a aprender. En cada una de las actividades que se desarrollen tienen de manera autónoma que asumir unas responsabilidades y unas normas. Los niños y las niñas toman decisiones y dan sus opiniones personales en todo momento. Cada uno explora, desarrolla y mejora sus posibilidades vocales y corporales, así como su creatividad e imaginación.

7. ${ }^{\circ}$ Conciencia y expresiones culturales: en esta unidad en concreto pretendo reforzar la técnica vocal que a lo largo de todo el año estoy trabajando con mi alumnado. Quiero que valoren su instrumento, que lo exploren y que lo sepan emplear sin hacerse daño.

Para ello parte de canciones que les pueden interesar y agradar. Vamos a reforzar la importancia de la lectura para el desarrollo íntegro de las personas y sobre todo mis alumnos y alumnas van a mejorar su imaginación y su creatividad de manera que su enriquecimiento en los aprendizajes sea mayor y significativo. En clase vamos a leer, escuchar música, vamos a cantar, vamos a bailar, también vamos a jugar y a divertirnos mientras trabajos de forma cooperativa.

Tabla 15. Objetivos de esta unidad

\begin{tabular}{|l|c|}
\hline \multicolumn{1}{|c|}{ Objetivos de la Unidad Didáctica } & $\begin{array}{c}\text { Real Decreto 126/2014 } \\
\text { Objetivos Generales de } \\
\text { etapa }\end{array}$ \\
\hline Memorizar una canción y cantarla de forma correcta & $\mathrm{B}, \mathrm{J}, \mathrm{K}, \mathrm{M}$ \\
\hline Entonar con propiedad una canción que han escuchado en clase & $\mathrm{B}, \mathrm{J}, \mathrm{K}, \mathrm{M}$ \\
\hline Ser capaz de relacionar un relato con lo aprendido en la sesión & $\mathrm{B}, \mathrm{J}, \mathrm{K}, \mathrm{M}$ \\
\hline $\begin{array}{l}\text { Memorizar una coreografía y puesta en escena para la canción } \\
\text { trabajada en clase }\end{array}$ & $\mathrm{B}, \mathrm{J}, \mathrm{K}, \mathrm{M}$ \\
\hline $\begin{array}{l}\text { Tener la capacidad de acompañar con percusión corporal una } \\
\text { canción }\end{array}$ & $\mathrm{B}, \mathrm{J}, \mathrm{K}, \mathrm{M}$ \\
\hline
\end{tabular}


- Mantener una actitud cooperativa y respetuosa hacia los demás

B,D,E, K, M compañeros y compañeras y hacia su profesora.

Bloque 1. Escucha:

\section{Real Decreto 126/2014 \\ ( Criterios de evaluación específicos de música)}

2. Analizar la organización de obras musicales sencillas y describir los elementos que las componen.

3. Conocer ejemplos de obras variadas de nuestra cultura y otras para valorar el patrimonio musical conociendo la importancia de su mantenimiento y difusión aprendiendo el respeto con el que deben afrontar las audiciones y representaciones

Bloque 2: La interpretación musical:

1. Entender la voz como instrumento y recurso expresivo, partiendo de la canción y de sus posibilidades para interpretar, crear e improvisar.

2. Interpretar solo o en grupo, mediante la voz o instrumentos, utilizando el lenguaje musical, composiciones sencillas que contengan procedimientos musicales de repetición, variación y contraste, asumiendo la responsabilidad en la interpretación en grupo y respetando, tanto las aportaciones de los demás como a la persona que asume la dirección.

Bloque 3. La música, el movimiento y la danza:

1. Adquirir capacidades expresivas y creativas que ofrecen la expresión corporal y la danza valorando su aportación al patrimonio y disfrutando de su interpretación como una forma de interacción social.

Estos seis objetivos se van adquirir una vez que mis alumnos y que mis alumnas interioricen, aprendan y generalicen en otros contextos de su vida cotidiana los contenidos que a continuación expongo en una tabla:

Tabla 16. Contenidos de la unidad

\begin{tabular}{|c|c|c|c|}
\hline $\begin{array}{c}\text { TIPOS DE } \\
\text { CONTENIDOS }\end{array}$ & \multicolumn{2}{|c|}{$\begin{array}{l}\text { Bloque 1. Escucha y } \\
\text { Bloque 2. Interpretación musical }\end{array}$} & $\begin{array}{l}\text { Bloque 3. La música, el } \\
\text { movimiento y la danza }\end{array}$ \\
\hline CONCEPTUALES & \multicolumn{2}{|c|}{$\begin{array}{l}\text { Canción infantil: La brujita Tapita } \\
\text { Estribillo } \\
\text { Percusión Corporal }\end{array}$} & $\begin{array}{l}\text { Canción infantil: } L a \\
\text { brujita Tapita } \\
\text { (coreografia) }\end{array}$ \\
\hline PROCEDIMIENTOS & \multicolumn{2}{|c|}{$\begin{array}{l}\text { Audiciones activas } \\
\text { Interpretaciones } \\
\text { Entonación de la canción } \\
\text { Ejecución de movimientos corporales }\end{array}$} & $\begin{array}{l}\text { Ejecución de } \\
\text { movimientos corporales } \\
\text { Repetición de } \\
\text { movimientos corporales }\end{array}$ \\
\hline ACTITUDINALES & \multicolumn{2}{|c|}{$\begin{array}{l}\text { Apreciación de una canción } \\
\text { Interés en la percusión corporal } \\
\text { Valoración del uso de su voz } \\
\text { Respeto hacia los demás }\end{array}$} & $\begin{array}{l}\text { Interés por realizar una } \\
\text { coreografía }\end{array}$ \\
\hline \multicolumn{4}{|c|}{ TIPOS DI } \\
\hline \multicolumn{2}{|c|}{ TRANSVERSALES } & \multicolumn{2}{|c|}{ INTERDISCIPLINARES } \\
\hline \multicolumn{2}{|c|}{$\begin{array}{l}\text { Educación en valores: cooperación, empatía, } \\
\text { tolerancia y respeto por uno mismo y por los } \\
\text { demás, cariño y amor a los compañeros }\end{array}$} & \multicolumn{2}{|c|}{$\begin{array}{l}\text { Lengua castellana y su literatura: cuatro } \\
\text { habilidades lingüísticas y el relato. } \\
\text { Ciencias Naturales: el cuerpo } \\
\text { Educación física: perfecciones espacial y }\end{array}$} \\
\hline
\end{tabular}


En cuanto a la metodología defiendo un aprendizaje constructivista en donde cada alumno con mi ayuda y la de sus compañeros y compañeras vaya construyendo sus aprendizajes, vaya adquiriendo valores para ejercer una ciudadanía democrática y sobre todo aprenda a aprender.

Por un lado, el papel de los alumnos debe ser muy participativo, cooperativo y activo pues apuesto por una enseñanza por descubrimiento, por resolución de problemas y una enseñanza en la que la comunicación en el aula sea multidireccional. Por otro lado, ninguna de mis sesiones está pensada para que las clases sean aburridas y sobre todo que el papel de mis alumnos sea pasivo.

También estará presente el método individualista debido a que mis discentes trabajarán de manera autónoma. Además de este cobra importancia el método socializado que estará presente en las actividades grupales, en las canciones interpretadas por toda la clase y también en la coordinación, ayuda grupal y cooperación que debe a ver en todas las sesiones.

El docente solo guía y apoya pero no trabaja por el alumno ni se dedica a dar clases magistrales. Lo importante es hacer a los alumnos y a las alumnas sean protagonistas de sus procesos de enseñanza y de aprendizaje.

Para llevar a cabo mis clases de música a lo largo de todo el curso escolar destaco que mis alumnos van a aprender las notas do, mi, sol y la con la ayuda de la fononimia propuesta por el gran pedagogo musical Zoltán Kodály (1882-1967).

Mi alumnado va a interiorizar el ritmo binario y la duración de la negra, corchea, blanca y sus silencios, con la ayuda de la percusión corporal que es muy útil para que los pequeños empiecen a crear y aprender música.

Finalmente, en mis sesiones tendré para el aprendizaje y para la memorización de una canción la ayuda de un musicograma. Esta idea la defendía el pedagogo musical Jos Wuytack (1935).

Esta forma de trabajar fue muy apreciada por el pedagogo Carl Orff (1895-1982). Además Orff defendía la idea de que hay que estudiar música de forma grupal y cooperativa y es así cómo mis alumnos, mis alumnas y yo vamos a aprender música. Emplearemos en las sesiones la percusión corporal para trabajar ritmos y memorizar las melodías $\mathrm{o}$ acompañamientos de nuestras canciones. En relación a cómo aprender una canción hay muchas formas de hacerlo según diferentes autores y autoras pero todos más o menos apuntan a lo que Ana de Mena González (1996: 84 y 85), nos enseña un método para que los niños y las niñas aprendan a cantar. Los pasos a seguir son ocho:

1. Se estudiará la letra y dicción leyendo la maestra la letra completa al niño explicándole su significado

2. Explicará las palabras nuevas (ejercicio de lenguaje)

3. A continuación se vocalizará cada verso, haciendo que el niño cuide su buena dicción

4. Silabeo rítmico ajustándose al ritmo de la canción. Es de gran importancia asegurar el ritmo

5. Sentir el ritmo de la canción por medio de palmas, pasos...destacando los pulsos

6. Audición de la canción. Iniciado el niño en el ritmo y la letra hacer que escuche la canción cuantas veces sean necesarias, hasta que se familiarice con la melodía 
7. Empezaremos por enseñar frase cortas separadamente y a continuación las uniremos todas hasta el final de la canción

8. Sugerencias musicales en torno a la canción como juegos y ritmos que la canción nos pueda sugerir o desarrollar la idea que la canción lleve en sí. (De Mena González Ana, 1996: 84 y 85).

Esta añade las condiciones para cantar en las aulas y dice que antes hayan realizado ejercicios de calentamiento, de respiración, de vocalización y de relajación. Hay que tener una posición correcta para el canto: cuerpo relajado, hombros en su sitio, piernas un poco abiertas (alineadas según los hombros) y cabeza recta, sin subirla o bajarla.

Debemos trabajar mediante la improvisación, en grupo y de pie y a través la memorización. Hay que estudiar poco a poco la canción siguiendo las pautas nombradas arriba. La canción se interpreta con una finalidad para que esta tenga sentido (mejorar las relaciones sociales, llevarla a un escenario, aprender música y otros conocimientos etc.) (De Mena González Ana, 1996:84-86).

\section{Sesión 1 (Martes 4 de mayo y miércoles 5 de mayo de 2015)}

- Lectura del relato ;Mirad la bruja Tapita!, narrado por la abuelita Manuelita

- Preguntas acerca del relato (conocemos a los personajes y pensamos en ellos) y opiniones. Hacemos un dibujo de la abuelita Manuelita y de una escena del relato (para casa, si en clase no da tiempo)

- Desarrollo de las actividades:

\section{Tabla 17. ACTIVIDADES DE INICIACIÓN 1}

\begin{tabular}{|c|c|c|c|}
\hline \multicolumn{4}{|c|}{ CALENTAMIENTO (6min) } \\
\hline Nombre de la actividad & Descripción & Recursos & Agrupamiento \\
\hline El pase de pelotas & $\begin{array}{l}\text { Todos se colocan en } \\
\text { círculo. El docente da una } \\
\text { pelota a los alumnos y a } \\
\text { las alumnas para que se la } \\
\text { pasen los unos a los otros } \\
\text { diciendo el nombre del } \\
\text { compañero o compañera } \\
\text { al que le pasan la pelota. } \\
\text { Vamos variando la voz en } \\
\text { altura, intensidad, } \\
\text { duración etc., con la que } \\
\text { decimos el nombre }\end{array}$ & $\begin{array}{l}\text { Dos pelotas de } \\
\text { goma- espuma }\end{array}$ & En gran grupo \\
\hline La danza de los animales & $\begin{array}{l}\text { Los niños y las niñas } \\
\text { imitan los movimientos y } \\
\text { el sonido del animal que } \\
\text { dice la profesora o el } \\
\text { profesor o un de sus } \\
\text { compañeros. Al terminar } \\
\text { reconocerán e imitarán los } \\
\text { sonidos de los animales } \\
\text { que escucharán del } \\
\text { ordenador }\end{array}$ & $\begin{array}{l}\text { Ordenador, internet o } \\
\text { pendrive para las } \\
\text { audiciones: } \\
\text { Los sonidos de los } \\
\text { animales - Juego } \\
\text { educativo para niños: } \\
\text { https://www.youtube. } \\
\text { com/watch?v=YxOr } \\
\text { QM21M-0 }\end{array}$ & \\
\hline
\end{tabular}




\section{Observaciones}

\section{$\mathbf{3}^{\circ} \mathbf{A}$}

La actividad ha sido motivadora para los alumnos y las alumnas. Quizás se ha alargado demasiado. Tendría que haber sido un calentamiento de 5 min y se ha hecho más largo.

De las dos actividades de calentamiento la de la danza de los animales es la que más les ha gustado.

El clima de trabajo ha sido el adecuado. Alguna vez que otra se ha tenido que esperar a que algunos y algunas guardaran silencio pero en general todo ha salido muy bien.

$\mathbf{3}^{\circ} \mathbf{B}$

En este curso sí he podido terminar mi sesión sin problema. No ha faltado tiempo aunque es verdad que he tenido que reducir el tiempo de calentamiento y de relajación. El clima de trabajo ha sido muy bueno, los niños y las niñas han realizado lo que les he pedido con muchas ganas y entusiasmo. Para la segunda sesión cambiaré la forma de leer el relato. Esta vez en vez de darles a ellos el relato voy a leérselo para que mantengan la escucha activa.

La actividad preferida ha sido la parte de aprendizaje de la canción. No he tenido que llamar la atención muchas veces.

Tabla16. ACTIVIDADES DE DESARROLLO 1

\begin{tabular}{|c|c|c|c|}
\hline \multicolumn{4}{|c|}{ Aprendizaje de la canción (33min) } \\
\hline Nombre de la actividad & Descripción & Recursos & Agrupamiento \\
\hline $\begin{array}{l}\text { Atención, atención a la } \\
\text { canción }\end{array}$ & $\begin{array}{l}\text { Todos se colocan sentados } \\
\text { en círculo. La profesora les } \\
\text { presenta la canción. } \\
\text { Para memorizarla y } \\
\text { aprenderla seguiremos } \\
\text { estos pasos. } \\
\text { Solo trabajamos una parte } \\
\text { de la canción: } \\
\text { Recitamos la letra } \\
\text { Escuchamos un párrafo: lo } \\
\text { hacemos con las vocales y } \\
\text { luego la letra (así con los } \\
\text { que trabajemos). } \\
\text { Reproducimos la letra } \\
\text { siguiendo cada uno la } \\
\text { melodía de forma } \\
\text { improvisada } \\
\text { Añadimos gestos. }\end{array}$ & $\begin{array}{l}\text { Fotocopias de la } \\
\text { canción, } \\
\text { audición de esta: } \\
\text { La bruja Tapita: } \\
\text { https://www.you } \\
\text { tube.com/watch } \\
\text { ?v=XTpWPVXI } \\
\text { RFE } \\
\text { Ordenador o } \\
\text { casset y } \\
\text { pendrive. }\end{array}$ & $\begin{array}{l}\text { Las repeticiones la } \\
\text { trabajaremos } \\
\text { individual, por } \\
\text { parejas y por } \\
\text { pequeños grupos }\end{array}$ \\
\hline ¡Manos a la obra! & $\begin{array}{l}\text { Ahora cantamos lo } \\
\text { aprendido con los gestos } \\
\text { pero por grupos. Cuando un } \\
\text { grupo canta, los demás solo } \\
\text { gesticulan. Después } \\
\text { cantamos todos juntos. } \\
\text { Juego 1: todos cantan al }\end{array}$ & $\begin{array}{l}\text { La bruja Tapita: } \\
\text { https://www.you } \\
\text { tube.com/watch } \\
\text { ?v=XTpWPVXI } \\
\text { RFE } \\
\begin{array}{l}\text { Ordenador o } \\
\text { casset y }\end{array}\end{array}$ & \\
\hline
\end{tabular}




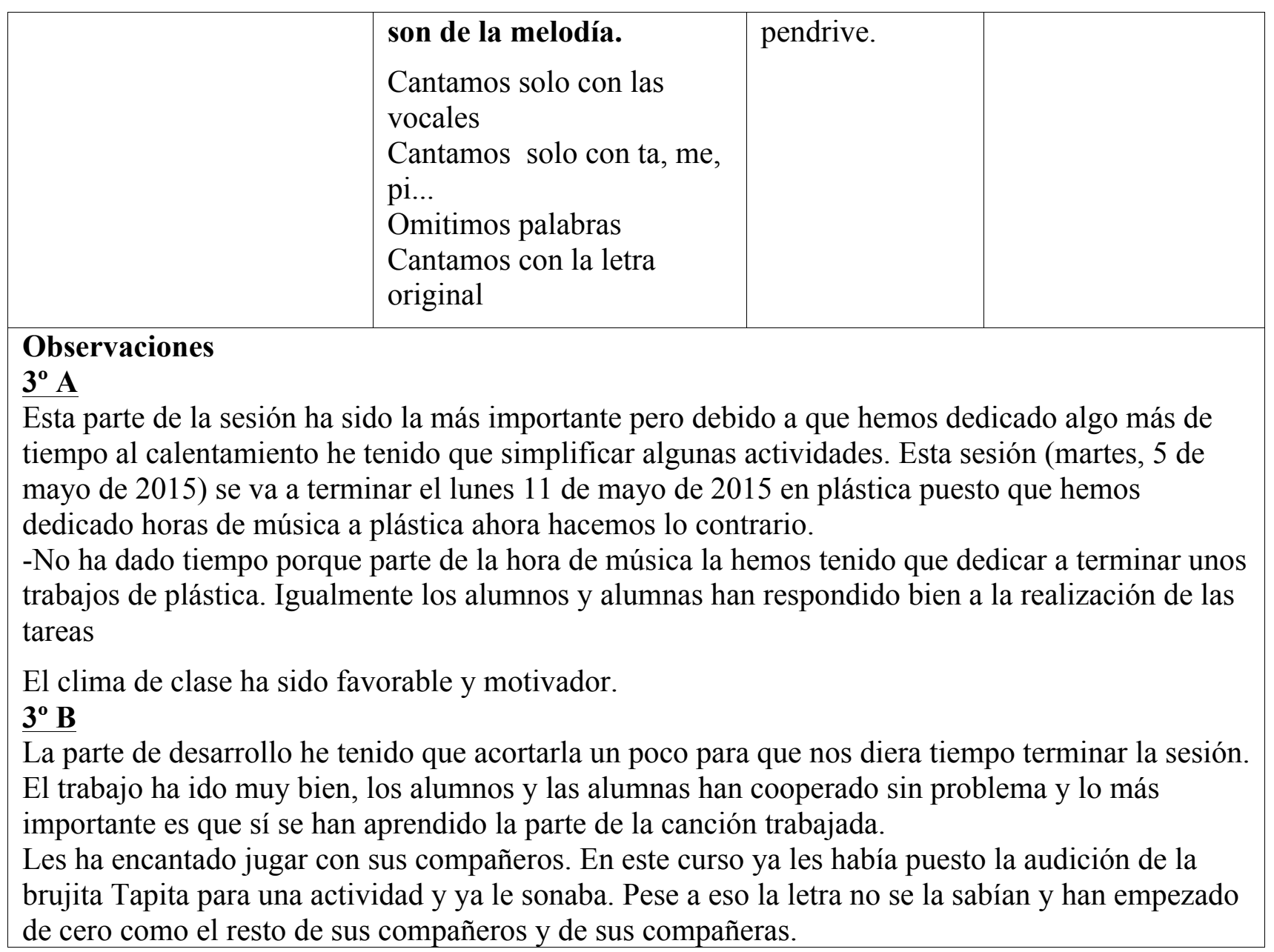

Tabla 18. ACTIVIDADES FINALES 1

\begin{tabular}{|c|c|c|c|}
\hline \multicolumn{4}{|c|}{ RELAJACIÓN (6min) } \\
\hline $\begin{array}{l}\text { Nombre de la } \\
\text { actividad }\end{array}$ & Descripción & Recursos & Agrupamiento \\
\hline Caminamos & $\begin{array}{l}\text { Todos caminan, al sonido de una } \\
\text { palmada cambian de dirección, al de } \\
\text { dos palmadas siguen caminando } \\
\text { agachados, a las tres palmadas van } \\
\text { muy agachados. Trabajamos la } \\
\text { atención. }\end{array}$ & & En gran grupo \\
\hline Oso dormilón & $\begin{array}{l}\text { Son osos tumbados en el suelo y } \\
\text { empiezan a mover lentamente las } \\
\text { partes de su cuerpo de izquierda a } \\
\text { derecha y de arriba hacia abajo sin } \\
\text { tensión. }\end{array}$ & $\begin{array}{l}\text { Ordenador, } \\
\text { internet } \\
\text { Música relax: } \\
\text { https://www. } \\
\text { youtube.com/ } \\
\text { watch?v=3PE } \\
\text { V1ztQkcs }\end{array}$ & en gran grupo \\
\hline \multicolumn{4}{|c|}{$\begin{array}{l}\text { Observaciones } \\
\frac{\mathbf{3}^{\mathbf{0}} \mathbf{A}}{\text { Esta parte de la sesión les ha gustado muchísimo porque se han relajado y han desconectado de la }} \\
\text { rutina del trabajo diario. Han terminado la clase con un aplauso muy motivador. Los alumnos y } \\
\text { alumnas se han sentido felices por las actividades que han realizado. La reflexión final ha sido muy }\end{array}$} \\
\hline
\end{tabular}


emotiva, me han comentado que se han sentido muy cómodos trabajando, que las actividades les han encantado sobre todo la de relajación, que la canción es muy divertida.

$\mathbf{3}^{\mathbf{0}} \mathbf{B}$

La parte de relajación les ha encantado, se han sentido muy bien y cómodos y lo importante se han ido a casa sin tensiones y totalmente relajados, cómo ellos y ellas me han dicho: "¡seño, estamos en una nube!". La reflexión final la hemos hecho oral. Todos han coincidido en que la clase ha sido divertida y se lo han pasado genial.

\section{Sesión 2 (Martes 12 de mayo de 2015 y miércoles 13 de mayo 201}

- Lectura del relato La brujita Tapita y Melodía van a la escuela narrado por la abuelita Manuelita

- Preguntas acerca del relato. Hacemos un dibujo de la historia.

- Desarrollo de las actividades:

Tabla 19. ACTIVIDADES DE INICIACIÓN 2

\begin{tabular}{|c|c|c|c|}
\hline \multicolumn{4}{|c|}{ CALENTAMIENTO (6min) } \\
\hline $\begin{array}{l}\text { Nombre de la } \\
\text { actividad }\end{array}$ & Descripción & Recursos & Agrupamiento \\
\hline ¿Qué canto? & $\begin{array}{l}\text { Cada niño tararea una canción y } \\
\text { el resto debe adivinarla. }\end{array}$ & & En gran grupo \\
\hline $\begin{array}{l}\text { ¡Trabalenguas y } \\
\text { poesías! }\end{array}$ & $\begin{array}{l}\text { Para trabajar la articulación van a } \\
\text { leer en parejas un trabalenguas y } \\
\text { una poesía. Caminando por clase. }\end{array}$ & Ficha & $\begin{array}{l}\text { En parejas y en gran } \\
\text { grupo. }\end{array}$ \\
\hline \multicolumn{4}{|c|}{$\begin{array}{l}\text { Observaciones } \\
\frac{\mathbf{3}^{\mathbf{O}} \mathbf{A}}{\text { En este curso he podido terminar el desarrollo de esta sesión. El calentamiento y la parte de }} \\
\text { relajación lo he realizado en menos tiempo, de esta forma la parte de desarrollo ha sido algo más } \\
\text { larga. Del calentamiento, la tarea más divertida para ellos ha sido la de los trabalenguas y las } \\
\text { poesías, en la primera actividad se han liado un poco al escoger una canción. } \\
\text { Los niños y las niñas han respondido muy bien. Solo dos alumnos han empezado a molestar a los } \\
\text { compañeros pero tras haberlos sentado unos minutos, se han incorporado y han participado sin } \\
\text { problemas. } \\
\mathbf{3}^{\mathbf{0}} \mathbf{B}\end{array}$} \\
\hline
\end{tabular}

TABLA 20. ACTIVIDADES DE DESARROLLO 2 Aprendizaje de la canción (33min)

\begin{tabular}{|l|l|l|l|}
\hline \multicolumn{1}{|c|}{$\begin{array}{c}\text { Nombre de la } \\
\text { actividad }\end{array}$} & \multicolumn{1}{|c|}{ Descripción } & \multicolumn{1}{|c|}{ Recursos } & Agrupamiento \\
\hline $\begin{array}{l}\text { ¿Cómo sigue la } \\
\text { canción? }\end{array}$ & $\begin{array}{l}\text { Todos se colocan sentados en } \\
\text { círculo. La profesora vuelve a } \\
\text { repartirles la letra de la canción. }\end{array}$ & $\begin{array}{l}\text { Fotocopias } \\
\text { La bruja Tapita: } \\
\text { Incorporando sus gestos a la } \\
\text { canción. }\end{array}$ & $\begin{array}{l}\text { Lasww.yout } \\
\text { repeticiones la } \\
\text { rem/watch?v } \\
\text { trabajaremos } \\
\text { individual, por } \\
\text { parejas y por }\end{array}$ \\
\hline
\end{tabular}




\begin{tabular}{|c|c|c|c|}
\hline & $\begin{array}{l}\text { Ahora seguimos la siguiente } \\
\text { parte de la canción: } \\
\text { Para memorizarla y aprenderla } \\
\text { tendremos seguir los mismos } \\
\text { pasos que en la sesión anterior. }\end{array}$ & $\begin{array}{l}\text { E } \\
\text { Ordenador o } \\
\text { casset y pendrive. }\end{array}$ & $\begin{array}{l}\text { pequeños } \\
\text { grupos }\end{array}$ \\
\hline ¡A jugar y a cantar! & $\begin{array}{l}\text { Ahora nos colocamos en tres } \\
\text { grupos. A cada grupo se le } \\
\text { asigna una letra. Empezamos a } \\
\text { cantar el párrafo nuevo, luego la } \\
\text { profesora irá indicando qué } \\
\text { grupo canta o sigue la canción. } \\
\text { Cantamos todos juntos con la } \\
\text { letra. } \\
\text { Juego 1: ¡Abracadabra patas } \\
\text { de cabra! } \\
\text { Los niños cantarán la nueva } \\
\text { estrofa, al llegar al estribillo no } \\
\text { pueden decir las palabras } \\
\text { mágicas “iabracadabra patas de } \\
\text { cabra!” tendrán que inventarse } \\
\text { otra. Quien diga “jabracadabra } \\
\text { patas de cabra!” se tendrá que } \\
\text { colocar en el fuego (dentro del } \\
\text { círculo) y al llegar las palabras } \\
\text { mágicas gritará jaaaayudaaa! Y } \\
\text { volverá a su sitio. }\end{array}$ & $\begin{array}{l}\text { Fotocopias de la } \\
\text { canción, audición } \\
\text { de esta: } \\
\text { La bruja Tapita: } \\
\text { https://www.yout } \\
\text { ube.com/watch?v } \\
=\text { XTpWPVXIRF } \\
\text { E } \\
\text { Ordenador o } \\
\text { casset y pendrive. }\end{array}$ & \\
\hline \multicolumn{4}{|c|}{$\begin{array}{l}\text { Observaciones } \\
\mathbf{3}^{\mathbf{0}} \mathbf{A} \\
\text { Las tareas les han gustado muchísimo, la que más trabajo les ha costado hacer bien desde el } \\
\text { principio es la del juego } 1 \text { porque algunos se despistaban y repetían las palabras mágicas. Para } \\
\text { trabajar los trabalenguas y las poesías, los alumnos y las alumnas han memorizado unos } \\
\text { ejemplos, no les he dado la ficha porque me interesaba que aprendieran de memoria algunos de } \\
\text { ellos y lo dijeran sin estar pendiente al papel. } \\
\mathbf{3}^{\mathbf{0}} \mathbf{B} \\
\text { En esta clase todo ha funcionado muy bien y han cogido al vuelo lo que tenían que hacer. A } \\
\text { algunos alumnos los he tenido que sentar porque no querían participar y se han puesto a } \\
\text { molestar. Al ver a sus compañeros y compañeras pasándose muy bien han decidido por ellos } \\
\text { mismos volver a trabajar y a jugar. }\end{array}$} \\
\hline
\end{tabular}

Tabla 21. ACTIVIDADES FINALES 2

\begin{tabular}{|l|l|l|l|}
\hline \multicolumn{1}{|c|}{$\begin{array}{c}\text { Nombre de la } \\
\text { actividad }\end{array}$} & \multicolumn{1}{|c|}{ Descripción } & Recursos & Agrupamiento \\
\hline $\begin{array}{l}\text { Las doce } \\
\text { campanadas }\end{array}$ & $\begin{array}{l}\text { El juego se ejercita formando un } \\
\text { corro, cerrando los ojos y } \\
\text { cogiéndose de las manos. } \\
\text { Consiste en levantar manos y } \\
\text { brazos hacia arriba y dejarlos } \\
\text { caer, al tiempo que se realiza }\end{array}$ & En gran grupo \\
\hline
\end{tabular}




\begin{tabular}{|c|c|c|c|}
\hline & $\begin{array}{l}\text { una inclinación hacia adelante y } \\
\text { se dice "dongggg". Tras las doce } \\
\text { campanadas de medianoche } \\
\text { llega el descanso. }\end{array}$ & & \\
\hline $\begin{array}{l}\text { Vals de las } \\
\text { mariposas }\end{array}$ & $\begin{array}{l}\text { Al son de la música, las } \\
\text { mariposas bailan con sus alas, } \\
\text { muy lentamente. Los niños } \\
\text { mueven sus brazos con suavidad } \\
\text { y con las articulaciones } \\
\text { relajadas. }\end{array}$ & $\begin{array}{l}\text { Ordenador, internet } \\
\text { o pendrive, Cd y } \\
\text { casset para las } \\
\text { audiciones. Música: } \\
\text { https://www.youtube } \\
. \text {.com/watch?v=3PEV } \\
1 \text { ztQkcs }\end{array}$ & En gran grupo \\
\hline \multicolumn{4}{|c|}{$\begin{array}{l}\text { Observaciones } \\
\frac{\mathbf{3}^{\mathbf{0}} \mathbf{A}}{\text { Esta parte es la que más les gusta de todas porque dicen que se relajan mucho. Por falta de tiempo }} \\
\text { y porque ellos me han pedido dedicarle más tiempo al primer juego, solo hemos hecho la } \\
\text { actividad de las } 12 \text { campanadas y se lo han pasado muy bien. En esta parte todos han participado } \\
\text { cumpliendo las normas del juego. (REVISAR EL DIARIO) } \\
\frac{\mathbf{3}^{\mathbf{0}} \mathbf{B}}{\text { En esta clase sí he podido realizar las dos actividades de relajación. Les ha gustado muchísimo }} \\
\text { pero al igual que a los otros compañeros y compañeras, les han gustado más la de las } 12 \\
\text { campanadas. }\end{array}$} \\
\hline
\end{tabular}

\section{Sesión 3 (Martes 19 de mayo y miércoles 20 de mayo de 2015)}

- Lectura del relato La brujita Tapita y su instrumento musical narrado por la abuelita Manuelita

- Preguntas acerca del relato (conocemos a los personajes y pensamos en ellos) y opiniones. Creamos un instrumento musical: necesitamos arroz, arena y globos de colores. Antes de hacer el instrumento inflamos y desinflamos el globo ¿Qué ocurre al respirar?

- Desarrollo de las actividades:

Tabla 22. ACTIVIDADES DE INICIACIÓN 3

\begin{tabular}{|l|l|l|l|}
\hline \multicolumn{3}{|c|}{ CALENTAMIENTO (6min) } \\
\hline Nombre de la actividad & \multicolumn{1}{|c|}{ Descripción } & Recursos & Agrupamiento \\
\hline ¿Cómo suena? & $\begin{array}{l}\text { Todos en círculo deberán de } \\
\text { imaginar y reproducir los sonidos } \\
\text { de: } \\
\text { - La sirena de una ambulancia } \\
\text { - Suena un fuerte viento } \\
\text { - Cuando arrancamos una moto etc. }\end{array}$ & En gran grupo \\
\hline Respira al ritmo del papel & $\begin{array}{l}\text { Mientras caminan por el aula } \\
\text { tendrán que ir rajando una hoja de } \\
\text { periódico a la vez que espiran. } \\
\text { Cuando inspiran no rompen nada } \\
\text { solo al soltar el aire. Cuando lo } \\
\text { rompan por la mitad, harán lo }\end{array}$ & $\begin{array}{l}\text { Hojas de } \\
\text { periódico }\end{array}$ & En gran grupo \\
\hline
\end{tabular}




\section{Observaciones}

mismo pero haciendo una bola.

$\mathbf{3}^{\mathbf{0}} \mathbf{A}$

Todo ha salido perfecto. La actividad dos les ha costado más trabajo hacerla, pero al final le han cogido el ritmo y se han divertido muchísimo. Hemos dedicado los minutos previstos. El juego de los sonidos ha sido fenomenal, los han reproducido muy similar a los reales y sin darse cuenta han vocalizado y han calentado la voz. Este juego es muy útil y les motiva.

$\underline{\mathbf{3}^{\circ} \mathbf{B}}$

La sesión se ha desarrollado bastante bien. En esta clase la segunda actividad ha ido peor porque no se concentraban y no conseguían hacerlo bien ciertos alumnos y alumnas. La primera actividad ha ido fenomenal, también me han sorprendido, los han imitado muy bien.

Tabla 23. ACTIVIDADES DE DESARROLLO 3

\begin{tabular}{|c|c|c|c|}
\hline \multicolumn{4}{|c|}{ Aprendizaje de la canción (33min) } \\
\hline $\begin{array}{l}\text { Nombre de la } \\
\text { actividad }\end{array}$ & Descripción & Recursos & Agrupamiento \\
\hline ¡Ya sé ha canción! & $\begin{array}{l}\text { Todos se colocan sentados en } \\
\text { círculo. La profesora vuelve a } \\
\text { repartirles la letra de la canción. } \\
\text { Vuelven a cantarla hasta el } \\
\text { final. }\end{array}$ & $\begin{array}{l}\text { Fotocopias } \\
\text { La bruja Tapita: } \\
\text { https://www.youtube } \\
\text { com/watch?v=XTp } \\
\text { WPVXIRFE } \\
\text { Ordenador. }\end{array}$ & $\begin{array}{l}\text { Las repeticiones } \\
\text { la trabajaremos } \\
\text { individual, por } \\
\text { parejas y por } \\
\text { pequeños grupos }\end{array}$ \\
\hline $\begin{array}{l}\text { ¡Vamos con la brujita } \\
\text { Tapita! }\end{array}$ & $\begin{array}{l}\text { Con percusión corporal } \\
\text { acompañarán su voz. Con las } \\
\text { maracas y otros instrumentos } \\
\text { simularemos que se hace el } \\
\text { hechizo. }\end{array}$ & & \\
\hline \multicolumn{4}{|c|}{$\begin{array}{l}\text { Observaciones } \\
\frac{\mathbf{3}^{\mathbf{O}} \mathbf{A}}{\text { Ha ido todo muy bien. La actividad que más les ha gustado es la de percusión corporal. }} \\
\frac{\mathbf{3}^{\mathbf{0}} \mathbf{B}}{\text { En este caso la actividad que más les ha gustado es la primera porque la de percusión corporal les }} \\
\text { ha parecido más difícil. Dos alumnos no se han portado muy bien y he tenido que llamarles la } \\
\text { atención varias veces. }\end{array}$} \\
\hline
\end{tabular}

Tabla 24. ACTIVIDADES FINALES 3

\begin{tabular}{|l|l|l|l|}
\hline \multicolumn{1}{|c|}{$\begin{array}{c}\text { Nombre de la } \\
\text { actividad }\end{array}$} & \multicolumn{1}{|c|}{ Descripción } & Recursos & $\begin{array}{c}\text { Agrupamie } \\
\text { nto }\end{array}$ \\
\hline $\begin{array}{l}\text { El juego de las } \\
\text { marionetas }\end{array}$ & $\begin{array}{l}\text { Se convierten en marionetas } \\
\text { (cuerpo con cierta rigidez } \\
\text { muscular), deben caminar con la } \\
\text { punta de los pies, con los brazos } \\
\text { tiesos a lo largo del cuerpo. A la } \\
\text { señal: se sueltan los hilos, los niños } \\
\text { tienen que doblar el cuerpo; la } \\
\text { cabeza y los brazos adquieren un } \\
\text { movimiento pendular. }\end{array}$ & $\begin{array}{l}\text { En gran } \\
\text { grupo }\end{array}$ & \\
\hline
\end{tabular}




\begin{tabular}{|c|c|c|c|}
\hline $\begin{array}{l}\text { Tumbados en el } \\
\text { suelo }\end{array}$ & $\begin{array}{l}\text { Ponemos las manos en nuestra } \\
\text { barriguita y respiramos suavemente } \\
\text { con los ojos cerrados. }\end{array}$ & $\begin{array}{l}\text { Ordenador } \\
\text { Música relax } \\
\text { https://www.youtube.c } \\
\text { om/watch?v=3PEV1zt } \\
\text { Qkes } \\
\text { https://www.youtube.c } \\
\text { om/watch?v=WwznI } \\
\text { Y1IeQ }\end{array}$ & $\begin{array}{l}\text { En gran } \\
\text { grupo }\end{array}$ \\
\hline \multicolumn{4}{|c|}{$\begin{array}{l}\text { Observaciones } \\
\mathbf{3}^{\mathbf{0}} \mathbf{A} \\
\text { La clase ha funcionado bien. Estas actividades finales siempre les gustan muchísimo y no hay } \\
\text { ningún problema de falta de atención y de concentración. } \\
\frac{\mathbf{3}^{\circ} \mathbf{B}}{\text { Los alumnos y las alumnas han colaborado y han cumplido como siempre las normas, les ha }} \\
\text { gustado la segunda actividad mucho más que la primera porque se han sentido más relajados. }\end{array}$} \\
\hline
\end{tabular}

Sesión 4 (Martes 26 de mayo y miércoles 27 de mayo de 2015)

- Lectura del relato ¿Qué dibuja Tapita cuando suena una música? narrado por la abuelita Manuelita

- Preguntas acerca del relato (conocemos a los personajes y pensamos en ellos) y opiniones.

- Desarrollo de las actividades.

Tabla 25. ACTIVIDADES DE INICIACIÓN 4

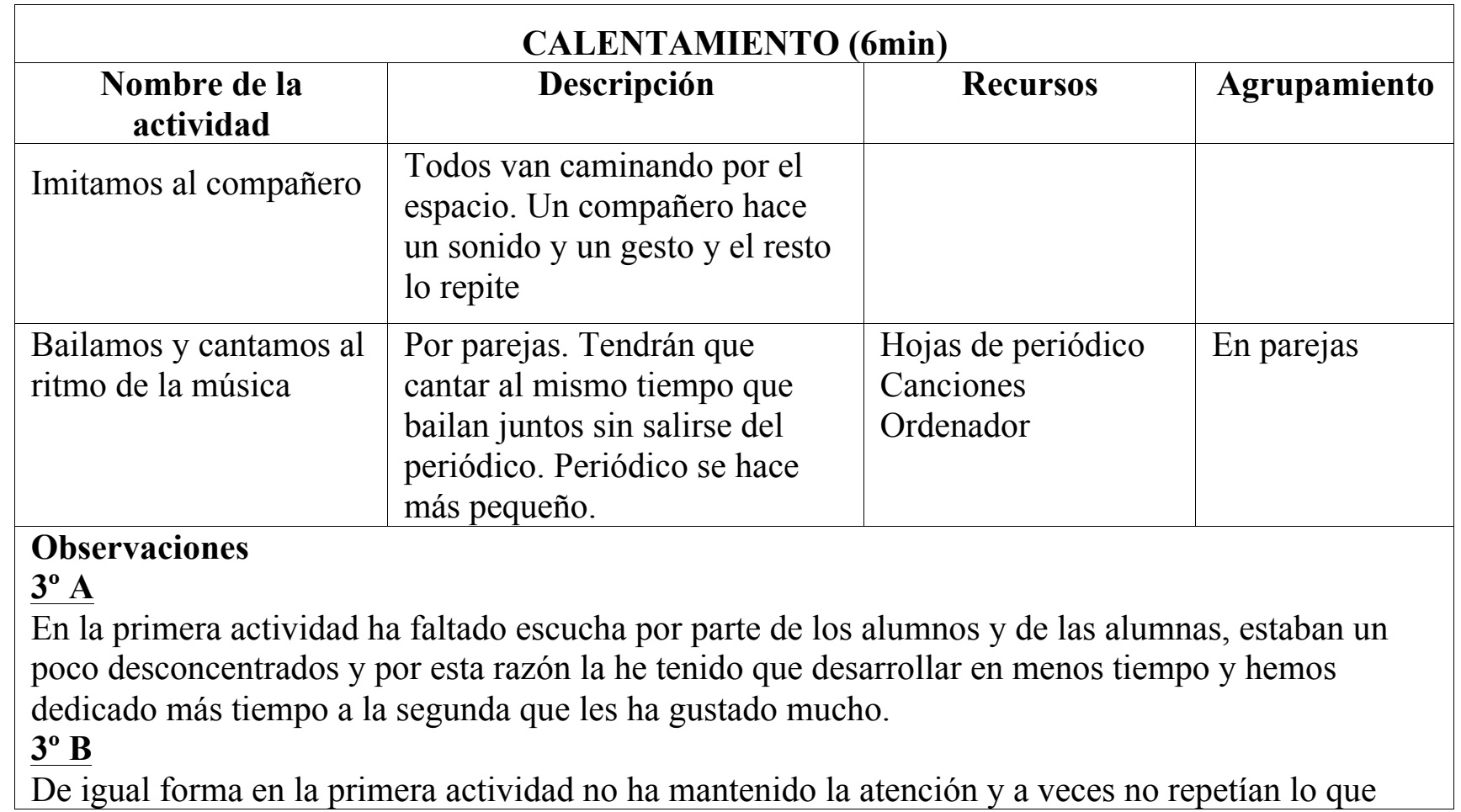


escuchan. También he tenido que hacerla en menos tiempo y pasar a la siguiente que ha funcionado bastante mejor.

El comportamiento ha sido bueno, no he tenido que llamar la atención. No hay nada importante que resaltar en esta parte.

Tabla 26. ACTIVIDADES DE DESARROLLO 4

\begin{tabular}{|c|c|c|c|}
\hline \multicolumn{4}{|c|}{ Aprendizaje de la canción (33min) } \\
\hline Nombre de la actividad & Descripción & Recursos & Agrupamiento \\
\hline ¡Los últimos retoques! & $\begin{array}{l}\text { Todos se colocan en } \\
\text { círculo. Escuchamos } \\
\text { la canción. Después } \\
\text { cantamos. }\end{array}$ & $\begin{array}{l}\text { Fotocopias } \\
\text { La bruja Tapita: } \\
\text { https://www.youtube.co } \\
\text { m/watch?v=XTpWPVX } \\
\text { IRFE }\end{array}$ & $\begin{array}{l}\text { En gran grupo o en } \\
\text { tres grupos }\end{array}$ \\
\hline $\begin{array}{l}\text { Nos disfrazamos de la } \\
\text { brujita Tapita }\end{array}$ & $\begin{array}{l}\text { Decoramos nuestra } \\
\text { máscara }\end{array}$ & $\begin{array}{l}\text { Fotocopias máscara y } \\
\text { decorados, purpurina y } \\
\text { colores. Tijeras y goma }\end{array}$ & Individual \\
\hline $\begin{array}{l}\text { ¡Ahora somos la brujita } \\
\text { Tapita! }\end{array}$ & $\begin{array}{l}\text { Cantamos e } \\
\text { interpretamos }\end{array}$ & $\begin{array}{l}\text { Audición. KARAOKE } \\
\text { Ordenador }\end{array}$ & \\
\hline \multicolumn{4}{|c|}{$\begin{array}{l}\text { Observaciones } \\
\mathbf{3}^{\mathbf{0}} \mathbf{A} \\
\text { Esta sesión he tenido que ampliarla y coger una hora de artística para acabarla porque es larga y } \\
\text { lleva su tiempo. Esta parte les ha gustado mucho porque a mis alumnos y a mis alumnas les } \\
\text { encantan dibujar y hacer manualidades. } \\
\mathbf{3}^{\mathbf{0}} \mathbf{B}\end{array}$} \\
\hline
\end{tabular}

Tabla 27. ACTIVIDADES FINALES 4

\begin{tabular}{|c|c|c|c|}
\hline \multicolumn{4}{|c|}{ RELAJACIÓN (6min) } \\
\hline $\begin{array}{c}\text { Nombre de la } \\
\text { actividad }\end{array}$ & Descripción & Recursos & Agrupamiento \\
\hline $\begin{array}{l}\text { ¿Qué me sugiere } \\
\text { la música? }\end{array}$ & $\begin{array}{l}\text { Colocamos a los niños } \\
\text { en grupos de trece o } \\
\text { doce en cada uno. Le } \\
\text { damos dos botes de } \\
\text { pintura a cada grupo y } \\
\text { papel continuo. Le } \\
\text { indicamos que al } \\
\text { ritmo de la música } \\
\text { tendrán que crear un } \\
\text { mural entre todos. }\end{array}$ & $\begin{array}{l}\text { Papel continuo (rollo de cinco } \\
\text { metros) } \\
4 \text { botes de pintura de dedos } \\
\text { Pañuelos de tela } \\
\text { Toallitas } \\
\text { Un cacharrito con agua } \\
\text { Música: } \\
\text { El lago de los cisnes de } \\
\text { Tchaikovsky: } \\
\text { https://www.youtube.com/watch?v } \\
\text { =CYFUiYoYPbg }\end{array}$ & $\begin{array}{l}\text { En dos grandes } \\
\text { grupos }\end{array}$ \\
\hline
\end{tabular}




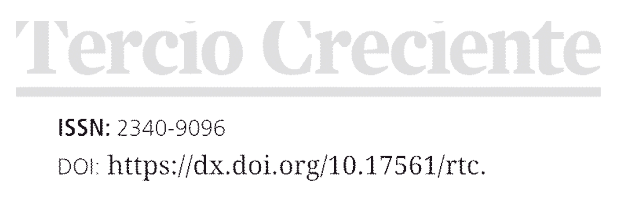

https://dx.doi.org/10.17561/rtc.n16.3

\section{Observaciones}

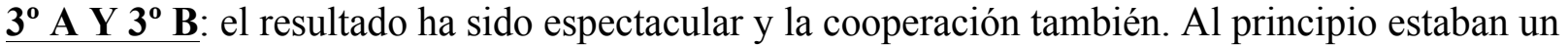
poco revolucionados, pero después toda ha marchado correctamente.

En cuanto a la evaluación destaco que gracias a los relatos de introducción evalué de forma inicial qué aspectos interesaban a mis alumnos y alumnas, qué les había sugerido el relato, qué esperaban trabajar, etc. Por lo tanto los relatos y sus actividades me sirvieron para hacer una evaluación inicial. También llevé a cabo una evaluación global y continua a lo largo de todas las sesiones para ello utilicé mi anecdotario personal, mis tablas de evaluación y la observación directa en el aula.

Anoté en cada una de las sesiones cómo trabajaban mis alumnos de manera individual y colectiva, qué dificultades encontraban durante las distintas tareas, qué contenidos habían de reforzarse o cuáles se habían adquirido de forma correcta, cómo se relacionaban unos con los otros y todo aquello que era útil para ver cómo iban progresando y qué habría que mejorar.

Finalmente, con mis notas, observaciones, con las evaluaciones diarias de cada sesión, con mis autoevaluaciones y las que realizaron mis alumnos y alumnas sobre su trabajo, más el resultado final de la canción aprendida incluida su representación, pude hacer la evaluación final global e individual de los discentes, así como también de mi propuesta para posibles mejoras.

\section{La puntuación a tener en cuenta fue:}

$\mathbf{5 0 \%}$ para el proceso seguido por el alumno.

Instrumentos de evaluación:

- Actividades del relato

- Plantillas de observación individual y grupal

- Anecdotario personal del profesorado

- Tabla de calificaciones de las actividades

- Autoevaluaciones diarias

$\mathbf{3 0} \%$ participación y actitud del alumno

$\mathbf{2 0 \%}$ puesta en escena (para la clase, profesores y profesoras y para Infantil)

Instrumentos de evaluación:

- Plantillas de observación individual y grupal

- Diario personal

- Autoevaluación del docente (apartado de actitud y respuesta del alumnado) y de los alumnos y alumnas.

\section{- Total: $\mathbf{1 0 0 \%}$}

\section{FASE 4: RESULTADOS DE LA INVESTIGACIÓN Y OBSERVACIONES DURANTE LA PUESTA EN PRÁCTICA}

Los resultados obtenidos han sido muy favorables y por ello creo conveniente ponerlos de manifiesto en este proyecto para que los docentes puedan tener ideas, recursos, 
metodologías y estrategias para trabajar sin miedo con las cualidades vocales de sus niños, teniendo en cuenta que todo se consigue con conocimiento, esfuerzo y regularidad.

Con esta investigación quiero defender la idea de que un ejercicio temprano del mecanismo respiratorio y fonador y de la relajación corporal y muscular reporta una serie de bienes para el posterior y correcto desarrollo de la voz del alumnado.

Una buena técnica vocal desde la etapa infantil supone beneficios a la salud, la socialización y la interacción con sus iguales. Profesionales de la educación y la medicina han realizado interesantes estudios sobre el tema de la voz infantil, su desarrollo, sus cuidados y su trabajo vocal para prevenir problemas como las disfonías infantiles.

Gracias a esto he podido extraer ideas, metodologías y juegos muy interesantes, innovadores y sobre todo adecuados a las etapas de Infantil y de Primaria. Una idea fundamental, la expresa Tulon Arfelis: "en la pedagogía vocal, las sensaciones fonatorias internas (sensaciones propioceptivas) son la guía de la que nos valemos para trabajar la voz”. (Tulon Arfelis, 2009: 152).

Trabajar la voz implica conseguir un desarrollo integral del alumnado ya que abarca el trabajo de otros muchos aspectos como la respiración, la relajación mental y física, la expresión de sentimientos, el desarrollo de valores sociales y la creatividad, que son imprescindibles en esta etapa.

La puesta en práctica de mi unidad didáctica en C.D.P. SAFA. De Linares (Jaén) ha sido una grata experiencia en la que he podido comprobar la efectividad de la técnica vocal en el aula de Primaria. El grupo con el que he trabajado ha respondido con motivación y ha participado de forma activa en cada una de las sesiones. Las calificaciones finales han sido positivas y se han conseguido los objetivos propuestos. Es necesario que el docente conozca las voces infantiles, sepa cómo se pueden poner en práctica los ejercicios vocales y tenga en cuenta los intereses y cualidades de sus discentes para que a partir de unas actividades de calentamiento, desarrollo y de relajación adaptadas y lúdicas podamos conseguir desarrollar una adecuada técnica vocal. Los resultados de esta experiencia educativa han sido óptimos poniendo de manifiesto que se puede adaptar la técnica vocal a la voz infantil, siguiendo unos criterios adecuados.

\section{Normativa Vigente}

LOMCE 8/2013 de 9/12 (Ley Orgánica para la Mejora de la Calidad educativa). [Acceso 18/04/2015], de: http://www.boe.es/boe/dias/2013/12/10/pdfs/BOE-A-2013-12886.pdf

Real Decreto 126/2014 de 28 de febrero. [Acceso 18/04/ 2015], de:

http://www.boe.es/boe/dias/2014/03/01/pdfs/BOE-A-2014-2222.pdf

\section{Referencias bibliográficas}

Plan del centro /Proyecto Educativo de C.D.P. SAFA. Linares

[Web en línea]. Campos Magda. (s.f.). Guía del niño. [Acceso 01/05/2015], de:

http://www.guiadelnino.com/juegos-y-fiestas/adivinanzas-chistes-trabalenguas/chistes-de-brujas-vampiros-y-

fantasmas

[Blogger en línea]. Sacra. (2013). El blog infantil. [Acceso 01/05/2015], de:

http://www.elbloginfantil.com/chistes-infantiles-celebrar-halloween.html

[Web en línea]. Caferri Agustina. (2015). Humor chupa sangre: 12 chistes de vampiros. About en español. [Acceso 01/05/2015], de: http://chistes.about.com/od/Chistes-por-tema/a/Chistes-De-Vampiros.htm [Blogger en línea]. Canal Euroresidentes. (2012). Blog mis chistes. Chistes Halloween. . [Acceso 01/05/2015], de:

http://mis-chistes.euroresidentes.com/2012/10/chistes-halloween.html 
https://dx.doi.org/10.17561/rtc.n16.3

[Web en línea]. El huevo de chocolate (1999- 2015). Trabalenguas para niños. [Acceso 02/05/2015], de: http://www.elhuevodechocolate.com/trabale1.htm

[Web en línea]. El huevo de chocolate (1999- 2015). Poesías para niños [Acceso 02/05/2015], de: http://www.elhuevodechocolate.com/poesias.htm

[Web en línea]. Garabata. (s.f.). Poesías Infantiles. [Acceso 02/05/2015], de:

http://pacomova.eresmas.net/paginas/poesias.htm

[Web en línea]. Rincónmaestro. (2000-2014). Poesía. [Acceso 02/05/2015], de:

http://www.rinconmaestro.es/lengua/poesia.html

[Blogger en línea]. García Jiménez $\mathrm{M}^{\mathrm{a}}$ Lourdes. (s.f.). Poesías para niños. [Acceso 03/05/2015], de: http://www.doslourdes.net/poes\%C3\%ADas_para ni\%C3\%B1os.htm

Arguedas Quesada, Consuelo. (2004). La expresión corporal y la transversalidad como un eje metodológico construido a partir de la expresión artística. Educación, 28, nº 1, 123-131.

Barrera Benjumea, $\mathrm{M}^{\mathrm{a}}$ Del Carmen. (2010). Uso didáctico y práctico de las canciones en Educación Infantil. 1 $^{\mathrm{a}}$ parte. Revista de Innovación y Experiencias Educativas. N 36, 1-9. De:

http://www.csi-

csif.es/andalucia/modules/mod ense/revista/pdf/Numero 36/M\%20DEL\%20CARMEN BARRERA 2.pdf

[Acceso 02/05/2016]

Bernal Vázquez, Julia y Calvo Niño, $\mathrm{M}^{\mathrm{a}}$ Luisa. (2000). Didáctica de la música. La expresión musical en la educación infantil. Málaga: Aljibe.

Bernal Vázquez, Julia y Calvo Niño, $\mathrm{M}^{\mathrm{a}}$ Luisa. (2004). Didáctica de la música: la voz y sus recursos: repertorio de canciones y melodías para la escuela. Málaga: Aljibe.

Bustos Sánchez, Inés. (1995). Tratamiento de los problemas de la voz. Madrid: Cepe.

Cabrera Padilla, Raquel. (2012). El canto como herramienta terapéutica para mejorar la salud emocional de la mujer. Universidad De San Carlos de Guatemala escuela de ciencias psicológicas centro de investigaciones en psicología-CIEPs- "Mayra Gutiérrez", 1-110.

Cáceres Guillén, $\mathrm{M}^{\mathrm{a}}$ Ángeles. (2010). La expresión corporal, el gesto y el movimiento en la edad Infantil. Revista Digital para profesionales de la enseñanza, 9, 1-7.

Cámara Izagirre, Aintzane. (2003). El canto colectivo en la escuela: una vía para la socialización y el bienestar personal. Revista de Psicodidáctica, № 15-16, 105-110.

Cámara Izagirre, Aintzane. (2005). Actitudes del niño hacia el canto. Musiker, 14, 101-119.

Cañete Pulido, $\mathrm{M}^{\mathrm{a}}$ Del Mar. (2009). La expresión corporal en la etapa de Infantil. El gesto y el movimiento. La expresión corporal como ayuda en la construcción de la identidad y de la autonomía personal. Juego simbólico y juego dramático. Las actividades dramáticas. . Innovación y experiencias educativas, 25, 1-11.

Cuart, Francisca. (2004). La voz como instrumento: Palabra y canto. Madrid: Real Musical.

De Mena González, Ana. (1994). Educación de la voz: principios fundamentales de la ortofonía. Archidona: Aljibe.

De Mena González, Ana. (1994). Educación de la voz: principios fundamentales de la ortofonía. Archidona: Aljibe

Díez Martínez, Marcelino. (1996). "Las voces infantiles. Extensión y tesitura de voz en niños de 7 a 14 años". De la Revista Tavira. De: http://rodin.uca.es/xmlui/handle/10498/7683 [Acceso 16/05/2016].

Dris Ahmed, Mariem. (2010). Actividades para desarrollar la inteligencia emocional en Educación Infantil. Innovación y Experiencias educativas, 33, 1-10.

Echevarría Goñi, Sagrario. (2008). La voz infantil. Educación y Reeducación. Evaluación y metodología para la relajación, la respiración, la articulación y la emisión vocal. Madrid: CEPE, S.L.

Escudero, Mª Pilar. (1987). Educación de la voz $2^{\circ}$. Madrid: Real Musical.

Heyning, L. (2011). "I can't sing!" The concept of teacher confidence in singing and the use within their classroom. International Journal of Education \& the Arts, 12(13).

Lago González, Tania. (2011-2012). La expresión corporal en Educación Infantil. Diseño y elaboración de una unidad didáctica. Universidad de Valladolid E.U. de Educación de Palencia. 
https://dx.doi.org/10.17561/rtc.n16.3

Lanas, Andrés. (2009). Manejo y tratamiento de la disfonía en niños y adultos: cuándo y cómo. De la Revista de medicina. CLIN. Condes. De:

http://www.clc.cl/Dev_CLC/media/Imagenes/PDF\%20revista\%20m\%C3\%A9dica/2009/4\%20julio/477_DISFO NIA-12.pdf [Acceso 11/05/2016].

Mansion, Madeleine. (1947). El estudio del canto. Buenos Aires: Ricordi.

Marín-Viadel, Ricardo y Roldán, Joaquín. (2014). "4 instrumentos cuantitativos y 3 instrumentos cualitativos en Investigación Educativa basada en las Artes Visuales”. Universidad de Granada. España, 1-40.

Molina Hurtado MT, Fernández González S, Vázquez de la Iglesia F, Urra Barandiarán, A. (2006). Voz del niño. Revista Medicina Universidad Navarra. Volumen 50, n³ 31-43. De: http://dadun.unav.edu/handle/10171/35894 [Acceso 16/05/2016].

Rodríguez Barquero, Vivian. (2008). El mejoramiento de la salud a través de la expresión corporal: Un enfoque holístico. Reflexiones, 87, $\mathrm{n}^{\circ}$ 1, 127-137.

Sanchidrián Pose, Rubén. (2013). Expresión corporal: Desarrollo de la desinhibición a través del juego. Segovia: Universidad de Valladolid. TFG.

Sanuy Montserrat. (1996). Aula sonora: hacia una educación musical en primaria. Madrid: Morata.

Tulon Arfelis, Carme. (2009). Cantar y hablar: conocimientos generales de la voz, técnica vocal, ejercicios, consejos básicos. Badalona: Paidotribo.

Willems Edgar. (1976). La preparación musical de los más pequeños. Buenos Aires: Eudeba. 